\title{
Firm-specific risk-neutral distributions: The role of CDS spreads
}

Aramonte, Sirio, Mohammad R. Jahan-Parvar, Samuel Rosen, and John W. Schindler

Please cite paper as:
Aramonte, Sirio, Mohammad R. Jahan-Parvar, Samuel Rosen,
and John W. Schindler (2017). Firm-specific risk-neutral
distributions: The role of CDS spreads. International Finance
Discussion Papers 1212.
https://doi.org/10.17016/IFDP.2017.1212

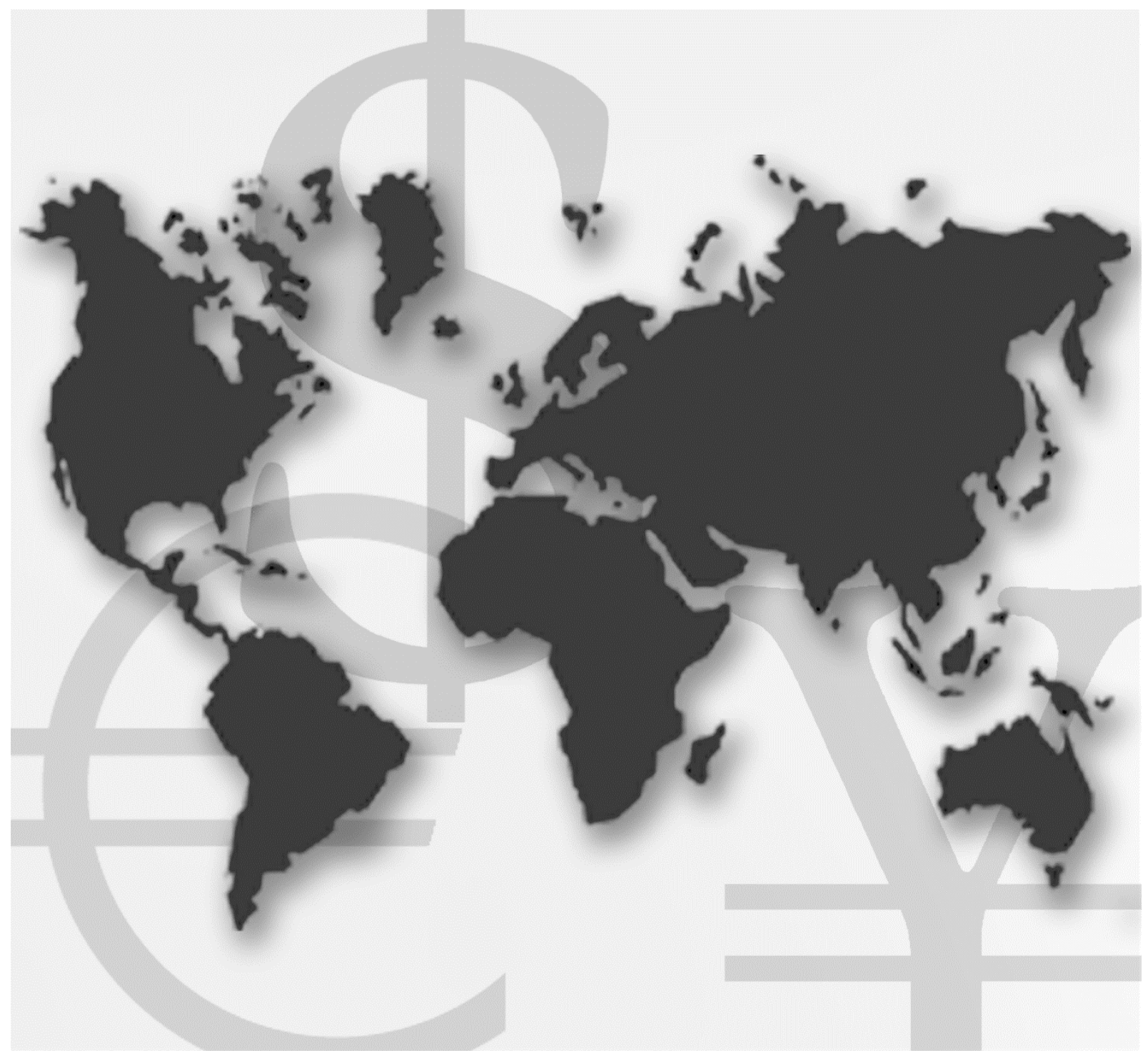

\section{International Finance Discussion Papers}

Board of Governors of the Federal Reserve System

Number 1212

August 2017 
Board of Governors of the Federal Reserve System

International Finance Discussion Papers

Number 1212

August 2017

Firm-specific risk-neutral distributions: The role of CDS spreads

Sirio Aramonte, Mohammad R. Jahan-Parvar, Samuel Rosen, and John W. Schindler

NOTE: International Finance Discussion Papers are preliminary materials circulated to stimulate discussion and critical comment. References in publications to International Finance Discussion Papers (other than an acknowledgment that the writer has had access to unpublished material) should be cleared with the author or authors. Recent IFDPs are available on the Web at https://www.federalreserve.gov/econres/ifdp/. This paper can be downloaded without charge from Social Science Research Network electronic library at http://www.sssrn.com. 


\title{
Firm-specific risk-neutral distributions:
}

\section{The role of CDS spreads}

\author{
Sirio Aramonte Mohammad R. Jahan-Parvar Samuel Rosen \\ John W. Schindler*
}

August 9, 2017

\begin{abstract}
We propose a method to extract individual firms' risk-neutral return distributions by combining options and credit default swaps (CDS). Options provide information about the central part of the distribution, and CDS anchor the left tail. Jointly, options and CDS span the intermediate part of the distribution, which is driven by moderatesized jump risk. We study the returns on a trading strategy that buys (sells) stocks exposed to positive (negative) moderate-sized jump risk unspanned by options or CDS individually. Controlling for many known factors, this strategy earns a $0.5 \%$ premium per month, highlighting the economic value of combining options and CDS.
\end{abstract}

Keywords: risk neutral distributions; CDS spreads; cross-section of expected returns

JEL classification: G12; G13; G14

*Aramonte, Jahan-Parvar, and Schindler are at the Federal Reserve Board. Rosen is at the University of North Carolina at Chapel Hill, Kenan-Flagler Business School. Contact author e-mail and phone number: sirio.aramonte@frb.gov, (202) 912-4301. We would like to thank Jack Bao, Daniel Beltran, Yasser Boualam, Stijn Claessens, Jennifer Conrad, Max Croce, Jesse Davis, Michael Gordy, Pawel Szerszen, and seminar participants at the Kenan-Flagler Business School, Federal Reserve Board, University of Warsaw School of Management, CFE 2016 (Seville), IFABS 2016 (Barcelona), JSM 2016 (Chicago), SNDE 2017 (Paris), Georgetown Center for Economic Research Biannual Conference (2017), North American Summer Meeting of the Econometric Society 2017 (St. Louis), and JSM 2017 (Baltimore). This article represents the views of the authors, and does not reflect the views of the Board of Governors of the Federal Reserve System or other members of its staff. 


\section{Introduction}

We propose a new method to extract the risk-neutral distribution of a firm's expected stock returns by combining the information contained in option prices and credit default swap (CDS) spreads. Options characterize the central part of the distribution, and CDS spreads anchor the left tail. Importantly, the joint use of option prices and CDS spreads allows us to shed light on the risk-neutral properties of large negative returns that, first, go beyond the strikes of actively traded options, and second, are not large enough to induce default. The literature on extracting option-implied return distributions has traditionally focused on broad equity indexes rather than on individual stocks, although interest in the latter has increased steadily in recent years. Unlike index options single-stock options tend to trade actively at strikes concentrated around the current price, hence they provide limited information about the non-central part of the return distribution. ${ }^{1}$

We apply our method to a sample of U.S. firms, and we conduct a series of asset pricing tests to document the economic value of extracting risk-neutral distributions using both option prices and CDS spreads. First, we compare our parametric approach with the established non-parametric methodology of Bakshi, Kapadia, and Madan (2003) (henceforth, BKM). We find that our procedure generally performs as well as BKM, and that it outperforms BKM in times of financial market stress. In addition, we focus on the contribution of CDS by studying a portfolio that buys (sells) stocks for which the options/CDS-implied skewness is higher (lower) than the option-implied skewness. The portfolio is long (short) on stocks that are sensitive to moderate-sized positive (negative) jump risk that is not spanned by options or CDS in isolation. We conduct time-series and cross-sectional asset-pricing tests to measure the economic significance of this factor, and find that it commands a $0.5 \%$ per month risk premium. We find that our results are robust to a large set of asset pricing fac-

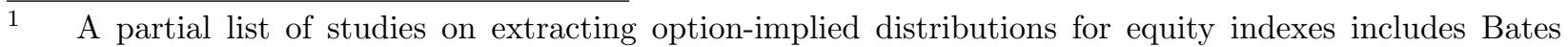
(1991), Madan and Milne (1994), Rubinstein (1994), Longstaff (1995), Jackwerth and Rubinstein (1996), Aït-Sahalia and Lo (1998), Bates (2000), Bliss and Panigirtzoglou (2002), Figlewski (2010), Birru and Figlewski (2012), and Andersen, Fusari, and Todorov (2015). Investors are net buyers of index options (Gârleanu, Pedersen, and Poteshman, 2009), and index options trade with more out-of-the-money (OTM) strikes than single-stock options since they provide hedge against increases in correlation that reduce the benefits of diversification (see Driessen, Maenhout, and Vilkov, 2009). 
tors, stock characteristics, and different assumptions about key inputs of the method, such as CDS tenor and default thresholds.

Studies of individual-stock risk-neutral distributions often build on the popular method of Bakshi and Madan (2000) and Bakshi, Kapadia, and Madan (2003) to calculate higherorder risk-neutral moments from option prices. Examples include Dennis and Mayhew (2002), Rehman and Vilkov (2012), Bali and Murray (2013), Conrad, Dittmar, and Ghysels (2013), DeMiguel, Plyakha, Uppal, and Vilkov (2013), and Stilger, Kostakis, and Poon (2017). Some implementations of this method rely on a potentially small number of options (e.g., Dennis and Mayhew, 2002, among others) or on interpolated option prices (e.g., An, Ang, Bali, and Cakici, 2014).

Our proposed method takes advantage of the availability of CDS contracts that were thinly traded in early 2000s. Since the mid-2000s, both the number and the liquidity of CDS contracts for U.S. companies have increased significantly. The estimation of risk-neutral distributions with options and CDS instead of just options can be advantageous for two reasons. First, CDS contain information about extreme events that liquid options, with strikes close to the current stock price, do not. This feature is especially valuable since we can anchor the left tail of the risk-neutral distribution through default probabilities embedded in CDS spreads. Second, considering CDS and options jointly can provide information that neither options nor CDS can convey individually. Using CDS and options together provides information about returns that, in absolute value, are large but not extreme. These returns are driven by moderate-sized jumps. ${ }^{2}$ The trade off we face is that we need data for both options and CDS, which reduces the sample size both in the cross section and in the time series. In addition, we need to estimate the return threshold where we transition from using options data to using CDS data.

A number of studies investigate the link between the pricing of options and CDS. Carr and $\mathrm{Wu}$ (2010) develop a model for the joint valuation of options and CDS, where the default rate is affected by stock volatility. They explicitly model the stock and default

2 Extreme negative jumps force a default, and in the company-specific context of our study, are accounted for by CDS-implied probabilities of default. 
dynamics, which entails estimating a relatively large set of parameters. Our approach imposes a less restrictive structure on the data. Our focus is on three parameters that characterize a skewed Student- $t$ distribution, which allows us to extract a new distribution for any day with a sufficient number of option prices. ${ }^{3}$ Carr and Wu (2011) derive a no-arbitrage relation between CDS and out of the money (OTM) put options that builds on the existence of a default corridor for stock prices. They assume that stock prices remain above a certain threshold before default, and jump below a second threshold upon default. A simple trading strategy that buys and sells options with strike prices within the default corridor has a payoff which mimics that of a CDS, thus establishing a no-arbitrage link between the prices of options and CDS. ${ }^{4}$

In order for our method to be feasible, stock prices need to be positive just before default. If stock prices always approach zero before default, bankruptcy would not span a meaningful set of a firm's equity return space, and the CDS-implied default probability could not be used to anchor the left tail of the risk neutral distribution of returns. There is evidence that debtholders generally have an incentive to strategically force a default before the value of assets approaches zero, in order to maximize the recovery rate on the debt (see Fan and Sundaresan, 2000, Carey and Gordy, 2016, and other references in Carr and Wu, 2011).

Our approach of using stock-specific moments to investigate the cross-section of returns contributes to an active line of research. In particular, our work is close to Stilger, Kostakis, and Poon (2017), Conrad, Dittmar, and Ghysels (2013) and Rehman and Vilkov (2012). These studies use the method developed in BKM to calculate risk-neutral higher moments for individual stocks and document the relation between the extracted moments and future

3 The skewed Student- $t$ distribution is often used to model financial time series, as in Hansen (1994) and Patton (2004).

4 A number of studies focus on the interaction between options or stocks and CDS or corporate bonds. The spreads on bonds and CDS are in theory linked through a no-arbitrage restriction. Among them, Friewald, Wagner, and Zechner (2014) show the CDS spread-term structure contains information about the equity premium. Cao, Yu, and Zhong (2010) document the covariation of CDS spreads and the volatility risk premium. Cremers, Driessen, and Maenhout (2008) and Cremers, Driessen, Maenhout, and Weinbaum (2008) find that option implied volatilities explain credit spreads. Acharya and Johnson (2007) find that information expressed in CDS spreads is reflected in stock prices with a lag. Ni and Pan (2011) study short-sale bans and highlight information flows from CDS to stock prices, while Han and Zhou (2011) document that the slope of the CDS term structure is related to subsequent returns, in particular for stocks for which arbitrage is more difficult. 
returns. Our results are in line with the findings of Stilger, Kostakis, and Poon (2017), Conrad, Dittmar, and Ghysels (2013) and Rehman and Vilkov (2012), but the design of our study differs from these papers along this important dimension: they are focused on the direct contribution of risk-neutral higher moments on future return predictability, while we are focused on the differential between options/CDS-implied and option-implied skewness.

The voluminous literature on index options has highlighted the importance of higher order moments for asset pricing since the mid-2000s. The literature on risk-neutral skewness is predated by studies on skewness extracted from historical returns. Harvey and Siddique (2000) find that systematic skewness helps explain the cross section of returns. Accounting for skewness is also important to identify the sign of the risk-return relation, see Feunou, Jahan-Parvar, and Tédongap (2013). Amaya, Christoffersen, Jacobs, and Vasquez (2015) find that realized skewness generates cross-sectional predictability in stock returns. Recently, Colacito, Ghysels, Meng, and Siwasarit (2016) investigate the effect of skewness in firm-level and macroeconomic fundamentals on stock returns. As documented by Kim and White (2004), measuring historical higher moments is difficult. Feunou, Jahan-Parvar, and Tédongap (2016), examine alternative parametric structures for skewness models, and Neuberger (2012) develops a realized estimator for skewness based on high-frequency data. Ghysels, Plazzi, and Valkanov (2016) use quantile-based measures of skewness to overcome data constraints in emerging markets. Khozan, Neuberger, and Schneider (2013) analyze skewness risk premium with a trading strategy that replicates a skew swap whose payoff is the difference between option-implied skewness and realized skewness. They find that variance risk and skewness risk are closely related, in that trading strategies which load on one of the two and hedge the other do not earn a risk premium.

The rest of the paper is organized as follows. Section 2 describes the data used in our study. In Section 3 we present the method for extracting the options/CDS-implied risk-neutral distributions. Section 4 discusses our empirical investigation and findings, and Section 5 concludes. 


\section{Data}

Our sample encompasses option prices, CDS spreads, and company stock returns from January 2006 to December 2015. We choose to focus on this period due to CDS data availability and reliability. Options and interest rate data are from OptionMetrics through Wharton Research Data Services (WRDS). We collect American options (with an "A" exercise style flag) written on individual common stocks (CRSP share codes 10 and 11) that trade on AMEX, NASDAQ, or NYSE (CRSP exchange codes 1, 2, and 3). As is customary with options data, we apply a series of filters to discard thinly-traded options and likely data errors. We keep observations with positive volume, positive bid and ask prices, and an ask price higher than the bid price. Following Santa-Clara and Saretto (2009), we drop options with a bid-ask spread smaller than the minimum tick (0.05 if the ask is less than 3, and 0.1 if the bid is more than or equal to 3). Finally, we discard options with missing observations for implied volatility.

The CDS data are from Markit. They include the term structure of CDS spreads between 6 months and 30 years, in addition to recovery rates and restructuring clauses. Moreover, Markit provides information on the reference obligation, including seniority and country of domicile for the issuer. We focus on U.S. Dollar-denominated CDS contracts on senior unsecured obligations issued by U.S.-based entities. We consider CDS spreads pertaining to contracts with an XR restructuring clause. Restructuring clauses determine what credit events trigger the payout of the CDS, and the XR clause excludes all debt restructuring as trigger events.

The bankruptcy data are from CapitalIQ, and we consider bankruptcy filings (event code 89) between 1990 and 2015. Some firms experience multiple bankruptcies, in which case we only include the first one, unless there is a five-year gap between bankruptcies.

We obtain stock returns from the Center for Research on Security Prices (CRSP) and balance-sheet items through Compustat. We manually match companies in Markit and CRSP by name, and we merge Compustat and OptionMetrics using the the lpermno and cusip variables. 
On any given day, we select the cross section of options with maturity closest to 90 calendar days, as long as the maturity is between 15 and 180 days. We require that the CDS spread and at least five option observations are available for each company/day combination. Table 1 shows selected summary statistics for the resulting 275 companies as of 2006 . These companies are large, with median book assets equal to about $\$ 13$ billion. The average of book assets is about $\$ 63$ billion, which indicates the presence of several very large companies. The remaining summary statistics are financial and balance sheet ratios, all scaled by book assets at the end of 2005, and show that there is substantial heterogeneity in our sample along several dimensions, including cash flows, sales, investment, research and development expense, and stock and debt issuance.

Although the companies in our sample are typically large, the strike coverage and traded volume of options written on their stocks remain pervasively low. The summary statistics in Table 2 highlight the differences in the availability of strike prices between options on the S\&P 500 index and on the companies we study. We apply the filters described earlier in this section to both index and stock options, and we define a call (put) option as OTM if the strike is above (below) the stock price. A put option is considered deep OTM if its strike price is less than $80 \%$ of the stock price.

The top panel of Table 2 shows that, for the S\&P 500, OTM options trade more often than their in-the-money (ITM) counterparts, with the average number of OTM options equal to 14.69 (puts) and 12.02 (calls) and the corresponding averages for ITM options equal to 4.29 (puts) and 5.40 (calls). The average daily number of deep OTM put options is about 8 , or roughly half the average number of OTM put options. Turning to individual-stock options in the bottom panel, the average number of option prices is considerably lower across both moneyess and call/put types, and there is little difference in availability between ITM and OTM options. The average number of deep OTM put options is roughly 2 , and the median equals 1.

Additionally, the two rightmost columns of Table 2 report summary statistics for option volume along moneyness and call/put types. We observe the same patterns that we discussed for the number of available options. Trading volumes are one order of magnitude 
smaller for individual-stock options compared to index options, and the difference is even more pronounced for OTM puts. Overall, the evidence in Table 2 point to the value of incorporating left-tail information from CDS spreads when studying the risk-neutral distributions of individual stocks.

\section{Options/CDS-implied return distributions}

Our method for estimating risk-neutral distributions is based on three ingredients: option prices, CDS spreads, and a default threshold. Option prices provide information about the central part of the distribution, while CDS spreads anchor the left tail. The probability of default embedded in the CDS contract is the cumulative density up to the default threshold. The default threshold pins the transition point between options- and CDS-based information. Figure 1 illustrates graphically how options and CDS information are combined to yield the risk-neutral distribution.

As highlighted in the previous section, options with a strike price close to the default threshold are very thinly traded. On the other hand, CDS contracts, especially since the mid-2000s, have an active market. By definition, CDS with an XR restructuring clause pay upon default, which means that their "strike price" is at the default threshold. Table 3 provides a hypothetical example of the typical availability of CDS and options with different strikes, and of the informativeness of CDS and options with different strikes about default risk. The current stock prices is $\$ 100$ and default happens when the stock price drops to $\$ 20$. Options with strike price close to the underlying price (strikes equal to $\$ 110$ and $\$ 90$ ) are actively traded but they are not informative about the probability of default. The reason is that these options speak to the probability of moderate price changes $( \pm 10 \%)$, however they do not provide information about significant price drops that could push the company into default. Single-name options with a strike price significantly below the current stock price and close to the default threshold ( $\$ 20$, in this case) rarely trade. Thus, while potentially informative, they are not readily available. CDS, on the other hand, have an implicit strike price that is equal to the default threshold and they are actively traded, hence they meet both requirements. 
For each stock/day pair, we estimate the parameters of a skewed Student- $t$ distribution (Hansen, 1994 and Patton, 2004) by minimizing the squared deviations between the empirical and parametric cumulative probability functions measured at the default threshold and at the option strike prices. The empirical cumulative probability at the default threshold is equal to the CDS-implied default probability, while the option-implied probabilities are computed using standard methods that build on the link between the call pricing function and the probability distribution highlighted in Breeden and Litzenberger (1978).

The probability density function of the skewed Student- $t$ distribution is given by:

$$
f\left(z^{j}\right)= \begin{cases}b c\left(1+\frac{1}{\eta-2}\left(\frac{b z^{j}+a}{1-\lambda}\right)^{2}\right)^{-(\eta+1) / 2} & \text { if } z^{j}<-a / b \\ b c\left(1+\frac{1}{\eta-2}\left(\frac{b z^{j}+a}{1+\lambda}\right)^{2}\right)^{-(\eta+1) / 2} & \text { if } z^{j} \geq-a / b\end{cases}
$$

where $\lambda(|\lambda|<1)$ is the shape parameter, $\eta(2<\eta<\infty)$ are the degrees of freedom, and $z^{j}=\frac{r^{j}-r^{f}}{\sigma^{j}}$ is the standardized return for company $j$ with expected return $r^{f}$ and volatility $\sigma^{j}$. Setting the expected return equal to the risk-free rate $r^{f}$ for all companies enforces the martingale restriction under the risk-neutral measure.

The skewness $s k$ and kurtosis $k u$ of the skewed Student- $t$ distribution are defined as follows (Feunou, Jahan-Parvar, and Tédongap, 2016):

$$
\left\{\begin{array}{l}
s k=\left(m_{3}-3 a m_{2}+2 a^{3}\right) / b^{3} \\
k u=\left(m_{4}-4 a m_{3}+6 a^{2} m_{2}-3 a^{4}\right) / b^{4}
\end{array}\right.
$$

where $a=4 \lambda c \frac{\eta-2}{\eta-1}, b=\sqrt{1+3 \lambda^{2}-a^{2}}, c=\frac{\Gamma((\eta+1) / 2)}{\Gamma(\eta / 2) \sqrt{\pi(\eta-2)}}, m_{2}=1+3 \lambda^{2}, m_{3}=16 c \lambda(1+$ $\left.\lambda^{2}\right) \frac{(\eta-2)^{2}}{(\eta-1)(\eta-3)}($ for $\eta>3)$, and $m_{4}=3 \frac{\eta-2}{\eta-4}\left(1+10 \lambda^{2}+5 \lambda^{4}\right)($ for $\eta>4)$.

Our goal is recovering risk-neutral distributions of three-month ahead expected returns. Options with a maturity of exactly three months are generally not available. As a result, for each day and for each company we choose the cross section of options with maturity closest to three months, as long as the maturity is between 15 and 180 days. Note that the risk-neutral cumulative density function ( $\mathrm{CDF}$ ) of returns is the first derivative of the European price function, but exchange-traded options on individual companies are Ameri- 
can options. We convert American prices into their European equivalent with three-month maturity by calculating the Black-Scholes price based on the implied volatility provided by OptionMetrics, which is computed according to a Cox, Ross, and Rubinstein (1979) binomial tree and does not incorporate the early exercise premium. In that, we follow Broadie, Chernov, and Johannes (2007).

\subsection{Option-implied return probabilities}

A number of contributions to the literature on option-implied distributions exploit the equality of the density to the scaled second derivative of the call price function with respect to the strike price (Breeden and Litzenberger, 1978). Other studies use binomial trees (Rubinstein, 1994, Jackwerth and Rubinstein, 1996) and kernel regressions (Aït-Sahalia and Lo, 1998).

Once away from at-the-money strikes, there are fewer options and those that are available are less liquid. Existing studies often obtain a denser set of option prices by interpolating/extrapolating the cross-section of implied volatilities (relative to strike prices) and inverting the set of traded and interpolated implied volatilities back to prices. The interpolation is often based on non-parametric techniques, like parabolic functions (Shimko, 1993) or cubic and quartic splines. The shape of the tails of the implied distributions depends crucially on the extrapolation method and on the leverage exerted by the implied volatilities at the extremes of the set of traded strikes. The literature has proposed to model the tails parametrically in order to limit this sensitivity (Shimko, 1993, Figlewski, 2010).

Our method for extracting the risk-neutral distribution of stock returns builds on the established literature that uses the first derivatives of the European call pricing function, relative to the strike price, to approximate the CDF of stock returns. We follow Figlewski (2010) when calculating the option-implied cumulative probabilities at the traded strikes, and we compute the cumulative probability at the default threshold using CDS spreads and the technique discussed in Section 3.3. We then estimate the parameters of a skewed Student- $t$ distribution by minimizing the squared deviations between the skewed Student- $t$ CDF and the cumulative probabilities extracted from options and CDS. 
For each company/day combination we have a cross section of call and put options with the same maturity. If both a call and a put option are available for the same strike price $i$, we compute the volume-weighted implied volatility as follows:

$$
I V_{i}=\frac{v_{i, C} \cdot I V_{i, C}+v_{i, P} \cdot I V_{i, P}}{v_{i, C}+v_{i, P}}
$$

where $v_{i, C}$ and $v_{i, P}$ are the call and put volumes, and $I V_{i, C}$ and $I V_{i, P}$ are the call and put implied volatilities. The volume associated with the weighted implied volatility is:

$$
v_{i}^{a v}=\frac{v_{i, C}^{2}+v_{i, P}^{2}}{v_{i, C}+v_{i, P}}
$$

Compared with a simple average, this formula ensures that the relative liquidity of the call and put options is appropriately taken into account. ${ }^{5}$

In line with the literature, we refer to implied volatilities as a function of strike prices as the volatility smile. Following Bliss and Panigirtzoglou (2002), we interpolate the volatility smile with a natural smoothing cubic spline before converting the implied volatilities to BlackScholes call prices. We use weights based on log-volume in the interpolation. We obtain the option-implied cumulative probabilities by taking finite differences of the interpolated BlackScholes European price function. We approximate the first derivative using points $0.1 \%$ to the left and right of the traded strikes. By doing so, we minimize the impact of the interpolation method on our results. The trade off is that we impose a parametric specification on the risk-neutral distribution.

\subsection{CDS-implied default probability}

In order to extract risk-neutral default probabilities, we need a model that links CDS spreads to the expected loss of the party selling default insurance. Building on Duffie (2003), we use a model where default risk has a constant hazard rate.

We can express the CDS spread in terms of the fee and contingent legs. The fee leg is

$5 \quad$ For instance, if the call-option volume is 100 and the put-option volume is 1 , the volume-weighted implied volatility mostly reflects the information contained in the call implied volatility. Taking the average of the option volumes would yield 50.5, while Equation 4 yields 99.02, which better represents the liquidity of the option that drives the average implied volatility. 
the expected value of the payments received by the protection seller. The contingent leg is the expected value of the losses incurred by the protection seller. As detailed below, we observe the CDS spread and all the variables that determine the value of the fee and contingent legs, with the exception of the hazard rate. This rate is computed numerically by equating the CDS spread to the ratio of the contingent and fee legs.

The value of the fee leg of a CDS with maturity $T_{N}$ and payment dates $\left\{T_{i}\right\}_{i=1}^{N}$ can be expressed as a function of the spread, $s$, the hazard rate, $\lambda$, the risk-free discount rate, $r_{i}^{f}$, and of the time between $T_{i-1}$ and $T_{i}\left(\Delta_{i}\right):^{6}$

$$
\begin{aligned}
V_{f}\left(\lambda, T_{N}\right) & =s \cdot \Sigma_{i=1}^{N}\left\{\Delta_{i} e^{-\lambda T_{i-1}}\left[e^{-\lambda \Delta_{i}}+\left(1-e^{-\lambda \Delta_{i}}\right) \frac{\lambda^{-1}-e^{-\lambda \Delta_{i}}\left(\Delta_{i}+\lambda^{-1}\right)}{1-e^{-\lambda \Delta_{i}}}\right] e^{-r_{i}^{f} T_{i}}\right\} \\
& =s \cdot \Sigma_{i=1}^{N}\left\{\Delta_{i} e^{-\lambda T_{i-1}}\left[e^{-\lambda \Delta_{i}}+\lambda^{-1}-e^{-\lambda \Delta_{i}}\left(\Delta_{i}+\lambda^{-1}\right)\right] e^{-r_{i}^{f} T_{i}}\right\}
\end{aligned}
$$

The first exponential in curly brackets is the survival probability up to time $T_{i-1}$. The expression in square brackets gives the expected fee between time $T_{i-1}$ and time $T_{i}$ : the firm survives one more period, in which case the full fee is collected; or the firm defaults, so that only the accrued premium is collected. The accrued premium is given by the spread times the expected time of default, conditional on default taking place in the interval $\Delta_{i}$, as captured by the fraction next to the closing square bracket. The last term in the formula is the discount factor.

The expected time of default, conditional on default taking place in the interval $\Delta_{i}$, is:

$$
\begin{aligned}
E\left[x \mid 0<x \leq \Delta_{i}\right] & =\int_{0}^{\Delta_{i}} x \frac{f(x)}{\int_{0}^{\Delta_{i}} f(x) \mathrm{d} x} \mathrm{~d} x=\int_{0}^{\Delta_{i}} x \frac{\lambda e^{-\lambda x}}{1-e^{-\lambda \Delta_{i}}} \mathrm{~d} x \\
& =\frac{1}{1-e^{-\lambda \Delta_{i}}} \lambda\left[\left.\frac{-x e^{-\lambda x}}{\lambda}\right|_{0} ^{\Delta_{i}}+\left.\frac{-e^{-\lambda x}}{\lambda^{2}}\right|_{0} ^{\Delta_{i}}\right] \\
& =\frac{\lambda^{-1}-e^{-\lambda \Delta_{i}}\left(\Delta_{i}+\lambda^{-1}\right)}{1-e^{-\lambda \Delta_{i}}}
\end{aligned}
$$

$6 \quad$ Our specification builds on Duffie (2003) and JPMorgan (2001). See the ISDA "Standard North American Corporate CDS Contract Specification" for details on the pricing and timing conventions for corporate CDS. 
The value of the contingent leg is:

$$
V_{c}\left(\lambda, T_{N}\right)=L \cdot \Sigma_{i=1}^{N}\left[e^{-r_{i}^{f} T_{i}}\left(e^{-\lambda T_{i-1}}-e^{-\lambda T_{i}}\right)\right]
$$

The par spread sets the value of the contract equal to zero at initiation, which means that the fee and the default legs have the same value. It follows that:

$$
s=\frac{L \cdot \sum_{i=1}^{N}\left[e^{-r_{i}^{f} T_{i}}\left(e^{-\lambda T_{i-1}}-e^{-\lambda T_{i}}\right)\right]}{\sum_{i=1}^{N}\left\{\Delta_{i} e^{-\lambda T_{i-1}}\left[e^{-\lambda \Delta_{i}}+\lambda^{-1}-e^{-\lambda \Delta_{i}}\left(\Delta_{i}+\lambda^{-1}\right)\right] e^{-r_{i}^{f} T_{i}}\right\}}
$$

Assuming that the loss given default $L$ is equal to 1 minus the recovery rate provided by Markit, all the variables in the equation except $\lambda$ are observable. We then recover the hazard rate as the value of $\lambda$ which verifies equation 8 .

In the baseline estimation we use the appropriately compounded spread on CDS with five years to maturity. The reason is that trading in corporate CDS is concentrated in the five-year tenor (Chen, Fleming, Jackson, Li, and Sarkar, 2011), which implies that spreads corresponding to CDS with other maturities are more likely to have a lower signal-to-noise ratio. Zhang, Zhou, and Zhu (2009) also focus on five-year CDS, for the same liquidity-

related reasons. In order to account for the slope in the CDS spread term structure, we also repeat our analysis using one-year CDS spreads and three-month CDS spreads. The three-month CDS contract, however, is not traded. We recover the three-month spread by linearly extrapolating from log-spreads with maturities between six months and ten years.

In principle, CDS spreads incorporate compensation for counterparty credit risk, which could induce upward bias in the measured default risk. However, Arora, Ghandi, and Longstaff (2012) [pg. 1] find that the effect is "vanishingly small and is consistent with [...] collateralization of swap liabilities by counterparties".

\subsection{Combining CDS- and option-implied probabilities}

We define the default threshold $\left(R_{D}\right)$ as the cumulative return over the three-month period leading to a bankruptcy filing for companies that delist within 30 days of bankruptcy. We identify Chapter 7 and Chapter 11 bankruptcy filings reported by CapitalIQ (event code 89) 
between 1990 and 2015, excluding companies with a market capitalization below $\$ 100$ million one year before the bankruptcy filing. For companies that default multiple times, only the first instance is included unless the bankruptcies are at least five years apart.

We first compute four different default thresholds by double sorting companies on the basis of market capitalization and leverage one year and one quarter before the bankruptcy filing. The market capitalization breakpoint is $\$ 1$ billion, and the leverage breakpoint is the bankruptcy-sample median. The rationale for using a five-quarter gap is that we need one quarter to calculate the default threshold, and we lag the firm characteristics by one year to limit the impact of the looming bankruptcy on market capitalization and leverage.

For robustness, we also consider three additional default thresholds. First, we take the average of the thresholds obtained by double sorting companies on the basis of size and leverage. Second, we use a threshold equal to $120 \%$ of the this average. Third, we set the threshold to $80 \%$ of the average. Evaluating the robustness to different default thresholds is also informative about the robustness of our results to different recovery rates, since both changing the threshold and changing the recovery rate ultimately alter the default probability extracted from CDS spreads.

Panel $\mathrm{A}$ in Table 4 reports the four default thresholds estimated by double sorting companies on size and leverage. The thresholds are expressed in both log and arithmetic returns. Large companies with low leverage experience noticeably more negative returns than small companies with high leverage in the run up to bankruptcy (-0.90 vs -0.70).

As shown in Panel B of Table 4, the mean of the four log-return thresholds equals -1.85, corresponding to -0.84 in arithmetic returns. The $120 \%$ and $80 \%$ of the mean are -2.23 and -1.48 , respectively. The corresponding arithmetic returns are -0.89 and -0.77 .

Sections 3.1 and 3.2 describe how we calculate the option-implied cumulative return probabilities and the CDS-implied default probability. Now we discuss how to combine these probabilities to estimate a parametric risk-neutral distribution of returns. We assume that, under the risk-neutral measure, returns follow a skewed Student- $t$ distribution. Hansen (1994) and Patton (2004) study financial applications of the skewed Student- $t$ distribution under 
the physical measure.

The skewed Student- $t$ CDF with parameter set $\Phi=\{\sigma, \lambda, \eta\}$ under the risk-neutral measure is represented by $F_{s k}(. ; \Phi)$. The CDS-implied cumulative probability up to the default threshold is $C P_{c d s}$, and the option-implied cumulative probability up to strike $s_{i}$ is $C P_{s_{i}}$. For each company/day combination, we estimate the parameters of a skewed Student- $t$ distribution by minimizing the squared deviations between the skewed Student- $t$ CDF and the cumulative probabilities extracted from options and CDS:

$$
\hat{\Phi}=\underset{\Phi}{\operatorname{argmin}}\left\{w_{c d s} \cdot\left[F_{s k}\left(R_{D}, \Phi\right)-C P_{c d s}\right]^{2}+\Sigma_{i=1}^{N} w_{s_{i}}\left[F_{s k}\left(s_{i}, \Phi\right)-C P_{s_{i}}\right]^{2}\right\},
$$

where $w_{c d s}$ is the weight assigned to the CDS-implied cumulative probability and $w_{s_{i}}$ is the weight assigned to the cumulative probability corresponding to strike $i$. If no option trades with a strike below $R_{D}$, each observation is equally weighted. If options trade with strikes below $R_{D}, w_{c d s}$ is equal to the volume of these options divided by the total option volume, and $w_{s_{i}}$ are equal weights scaled so that $w_{c d s}+\sum_{i=1}^{N} w_{s_{i}}$ sums to one. The mean of the risk-neutral distribution is set to the risk-free rate to enforce the martingale restriction. ${ }^{7}$

We repeat the above procedure (equation 9) using only option-implied cumulative probabilities, effectively setting the term $\left[F_{s k}\left(R_{D}, \Phi\right)-C P_{c d s}\right]^{2}$ equal to zero. As a result, on a given day and for a given company, we recover one risk neutral distribution based on options and CDS, and another distribution based on options only.

We recover the skewed Student- $t$ parameters by repeating the estimation procedure 10 times after randomizing the starting values. We then carry out a grid search centered around the parameter set $\tilde{\Phi}=\{\tilde{\sigma}, \tilde{\lambda}, \tilde{\eta}\}$ which yields the smallest squared deviations. The skewed Student- $t$ distribution is characterized by three parameters (as discussed above, the mean is set to the risk-free rate to satisfy the martingale restriction). We constrain the volatility, shape, and degrees of freedom parameters to be between [0.05,1.25], [-0.995,0.995], and $[2.1,100]$, respectively. For the volatility and shape parameters, the grid search is focused on \pm 0.05 around $\tilde{\sigma}$ and $\tilde{\lambda}$, in 0.005 steps. For the degrees of freedom, we focus on \pm 0.1 around

$7 \quad$ In order to reduce the influence of outliers, we discard options with strikes that imply a return below $R_{D}$ and, for symmetry, options with strikes that imply a return above the opposite of $R_{D}$. 
$\tilde{\eta}$, in 0.01 steps.

\section{Empirical investigation}

In this section, we present the empirical evidence in support of our proposed method. To do so, we proceed as follows. First, we discuss the properties of the skewed Student- $t$ moments extracted using options and options and CDS and of the moments based on the non-parametric method of Bakshi, Kapadia, and Madan (2003), which is the standard approach in this literature. We evaluate which risk-neutral moment is more directly affected by the inclusion of CDS. We find it to be skewness. Second, we focus on skewness and, in order to assess the economic value of our method, we perform a set of asset pricing tests on portfolios formed on the basis of various skewness measures and on the difference between the options/CDS and options-only skewness. Our analysis is in line with other studies in this literature, which investigate the asset-pricing implications of option-implied skewness (Stilger, Kostakis, and Poon, 2017, Conrad, Dittmar, and Ghysels, 2013, and Rehman and Vilkov, 2012, among others). Third, we conduct robustness tests that evaluate the impact of choosing alternative CDS tenors and of using different default thresholds.

We choose to evaluate our method with asset pricing tests for three reasons. First, studying risk-adjusted returns is a simple way of evaluating the economic significance of the method we propose because risk-adjusted returns are a direct measure of how much investors care about the risk expressed by our skewness measure. Second, due to data limitations, our panel of firm/day risk-neutral moments is unbalanced. For the median company, we can calculate risk-neutral moments on $34 \%$ of the business days. ${ }^{8}$ At the $10^{\text {th }}$ and $90^{\text {th }}$ percentiles, we can calculate risk-neutral moments on $12 \%$ and $68 \%$ of the business days, respectively. By forming portfolios and studying returns, we obtain continuous time series that also smooth out estimation noise. As a final step, as clear from the summary statistics we discuss below, the risk neutral moments we estimate contain a certain number of extreme observations. These observations are bound to exert significant leverage in, for instance, a comparison of risk-neutral moments with future realized moments. Using skewness to form

We follow the New York Stock Exchange convention for the number of business days each year. 
stock portfolios and studying the returns of these portfolios avoids econometric issues, since stock returns are well behaved. We could discard extreme observations. However they could contain economic information about investment opportunities - our sample includes the 2008 financial crisis and the ensuing high-volatility years. In portfolio-based tests, we let these observations inform portfolio formation without worrying about econometric issues.

We conduct asset-pricing tests using monthly returns. We assign companies to portfolios based on moments as of the end of the previous month. In order to smooth potential estimation noise, while also retaining timely information, we average the moments over the last three days of the month (Stilger, Kostakis, and Poon, 2017 also use end-of-month moments).

Including CDS in the estimation of the risk-neutral distributions does not necessarily lead to very large changes in the shape of the density function. Figure 2 provides an example. This figure plots the options-only and options/CDS risk-neutral densities for Citigroup Inc. on July 20, 2009. As is clear from the figure, the inclusion of CDS has a noticeable effect on the shape of the risk-neutral distribution.

\subsection{Risk-neutral moments and the inclusion of CDS}

In order to understand which moment of the risk-neutral distributions is primarily affected by the inclusion of CDS, we compare the moments of options/CDS and options-only riskneutral distributions. We expect CDS to affect kurtosis and skewness more than volatility, since the latter is well characterized by options with strike prices around the current stock price. Kurtosis, on the other hand, measures the thickness of tails, which is directly linked to the default probability expressed by CDS spreads. Skewness measures the shape of a distribution, which is influenced by both the central part and the tails.

For each moment (volatility, skewness, and kurtosis), we construct the absolute difference between the options/CDS moment and the options-only moment, scaled by the absolute

value of the options-only moment $\left(\frac{\left|m_{o p t / C D S}-m o m_{o p t}\right|}{\left|m o m_{o p t}\right|}\right)$. Panel A of Table 5 shows the average and upper percentiles of the absolute relative differences' distribution. It is immediately 
clear that, first, the moment most affected by the inclusion of CDS is skewness, followed by kurtosis. Second, we observe that meaningful differences between the options/CDS and options-only skewness are concentrated above the $75^{\text {th }}$ percentile.

The estimation of risk-neutral distributions with options and CDS instead of just options can be advantageous for two reasons. First, CDS contain information about extreme events that liquid options, with strikes close to the current stock price, do not. This information directly affects the estimation of kurtosis. Second, considering CDS and options jointly can provide information that neither options nor CDS can convey individually. Figure 1 illustrates that the default probability implied by CDS spreads pins down the far left tail, and that options are informative about the central part of the distribution. The intermediate part of the distribution is not spanned by either CDS or options in isolation. However, using CDS and options together provides information about returns that, in absolute value, are large but not extreme. This information affects the estimation of skewness.

The information about probabilities of default embedded in CDS spreads directly affect kurtosis. This information indirectly affect skewness, and only in conjunction with options data. As a result, we expect CDS spreads to explain the difference between options/CDS and option-only kurtosis to a larger extent than they explain the difference between options/CDS and options-only skewness. We expect this to be the case even though skewness is the moment that changes by inclusion of CDS in recovering of risk neutral distributions. In Panel B of Table 5, we report the results of regressing $s k_{\text {opt } / C D S}-s k_{\text {opt }}$ or $k u_{\text {opt } / C D S}-k u_{\text {opt }}$ on 5-year CDS log spreads. The regression results point to stronger direct influence of CDS on kurtosis than on skewness, even though skewness is more affected than kurtosis by the inclusion of CDS in the procedure for extracting risk-neutral densities, as shown in Panel A. When focusing on non-zero differences, the slope parameter for CDS spreads is statistically significant only for kurtosis. This coefficient becomes statistically significant for skewness only when the differences become increasingly larger. The magnitude and statistical significance of the slope coefficient, as well as the $\mathrm{R}^{2} \mathrm{~s}$, are always larger for kurtosis than for skewness.

Considering the evidence presented in Panels A and B, one can easily conclude that joint consideration of options and CDS influences skewness more than kurtosis. As a result, 
in the remainder of the paper we focus on skewness. Moreover, Stilger, Kostakis, and Poon (2017), Conrad, Dittmar, and Ghysels (2013), and Rehman and Vilkov (2012) find that firmspecific risk-neutral skewness is priced in the cross-section of stock returns, which makes skewness of particular interest to the finance community.

We interpret our results in terms of moderate-jump risk that is unspanned by options or CDS individually. We provide empirical evidence to this effect in Section 4.3. An active line of research in financial economics studies the link between conditional skewness and jumps. Recent examples include Patton and Sheppard (2015), Bandi and Renò (2016), and Feunou, Jahan-Parvar, and Okou (Forthcoming). These studies focus on aggregate stock market returns, and as such, investigate both large and medium-scale jumps. In our framework, we consider the link between medium-scale jumps and skewness, since the risk of large jumps that can push a company into bankruptcy is captured by CDS spreads.

\subsection{Evaluating measures of risk-neutral skewness}

In Panel A of Table 6, we report summary statistics for skewness measures extracted from options and CDS, from options only, and for the difference between the two. These moments are recovered using our parametric method. In Panel B, we compare the non-parametric skewness measure of Bakshi, Kapadia, and Madan (2003) (henceforth, BKM), as implemented by Conrad, Dittmar, and Ghysels (2013), to our options/CDS and options-only measures. As shown in Panel A, differences between the options/CDS and options-only measures are concentrated in the tails. Panel B highlights that the BKM skewness measure is generally comparable to ours. However, there are noticeable differences between BKM's measure and ours, especially in the tails.

In what follows we compare the BKM, options-only, and options/CDS skewness using the returns on portfolios formed on each measure. Each portfolio is long (short) stocks in the top (bottom) $25 \%$ of the skewness distribution at the end of the previous month. Figure 3 shows the cumulative returns on the three skewness portfolios and the UMD momentum portfolio of Carhart (1997). The returns on the options/CDS (SKEW $\left.\mathrm{Spt}_{\text {CDS }}\right)$ and options-only $\left(\mathrm{SKEW}_{\text {opt }}\right)$ portfolios are similar, but not identical. The BKM portfolio $\left(\mathrm{SKEW}_{B K M}\right)$ tracks 
the two other skewness portfolios closely until early 2009. However, the portfolios based on our parametric skewness measures outperform the non-parametric BKM portfolio through 2009. This performance gap only starts to close in late 2014. Since the options/CDS and options-only portfolios have similar cumulative returns, the outperformance of the portfolios based on our method relative to BKM is not driven by the inclusion of CDS. The substantive difference seems to lie with our use of a parametric method to recover risk-neutral distributions.

We test the relationship between the BKM and options/CDS portfolio returns formally, by regressing options/CDS-portfolio returns on BKM-portfolio returns and a set of additional risk factors, including the five Fama and French (2015) factors, changes in the spread of the CDS-index CDX High Yield (to capture economy-wide default risk), and a factor-mimicking portfolio for changes in the implied volatility index (VIX). Using a factor-mimicking portfolio for VIX changes allows us to interpret the intercepts of the time-series regressions as riskadjusted average returns. ${ }^{9}$ We report our findings in Panel A of Table 7. The coefficients on the BKM portfolio are statistically significant both in the full sample and in the 20082011 sample, which focuses on the global financial crisis and its immediate aftermath. The statistical significance of the estimated intercept in the 2008-2011 period implies that the returns on the options/CDS factor are not fully explained by the other factors included in the regression model. This result is consistent with the evidence presented in Figure 3, which shows that the options/CDS factor outperforms the BKM factor precisely in the aftermath the 2008 financial crisis.

A possible reason for the options/CDS and options-only portfolios outperforming the BKM portfolio throughout 2009 is that the parametric nature of our method enables us to more efficiently extract information about future investment opportunities. Indeed, early

$9 \quad$ The factor mimicking portfolio is built using stocks for which we can calculate the volatility spreads of Bali and Hovakimian (2009) and the implied-volatility smirk of Xing, Zhang, and Zhao (2010). These stocks are also used to replicate the 25 size/book-to-market portfolios of Fama and French (1993) that we use in the cross-sectional asset pricing tests discussed in Section 4.4. We regress monthly stock returns in excess of the risk-free rate on the three Fama and French (1993) factors plus momentum, and changes in VIX, changes in VIX squared, and the variance risk premium of Bollerslev, Tauchen, and Zhou (2009) over the 2006-2015 time period. The equally-weighted replicating portfolio is long (short) stocks whose factor loadings on VIX changes are in the top (bottom) $25 \%$ of the distribution. 
2009 is when the stock market bottomed out and a sustained recovery commenced. We can make an interesting comparison of the returns on the options/CDS and options-only portfolios with the momentum strategy. As discussed by Barroso and Santa-Clara (2015) and Daniel and Moskowitz (2016), and as shown in Figure 3, the momentum strategy experienced very poor returns through 2009. Momentum is a backward-looking strategy that performs poorly when confronted with sharp changes in the business cycle. At the end of a long recession, like the one that began in December 2007, the momentum strategy would buy stocks that have performed well (e.g., low-beta stocks) and sell stocks that have performed poorly (e.g., highbeta stocks). After a sharp change in the business cycle and in the stock market trend, and for a length of time that depends on the portfolio-formation period, the momentum strategy would keep buying (selling) stocks that have done relatively well during the recession but that will perform relatively poorly with the new upward trend (e.g., the strategy would keep buying low-beta stocks and selling high-beta stocks).

To the extent that our method extracts information about future investment opportunities efficiently, the returns on the portfolios based on the options/CDS and options-only skewness measures should be negatively correlated with the returns on the momentum strategy during the year 2009. The top panel in Figure 4 shows that such is the case. The returns on the options/CDS portfolio are clearly negatively correlated with momentum returns, and the most negative momentum return (April 2009) corresponds to the largest return on the options/CDS portfolio. The bottom panel of this figure shows that the correlation between momentum and BKM skewness portfolio returns is far less pronounced.

We formally test the relationship between the momentum strategy and options/CDS or the BKM skewness, by regressing momentum portfolio returns on options/CDS or the BKM portfolio returns, along with the same risk factors used to evaluate the relationship between the two skewness portfolio returns. Panel B of Table 7 reports these results. As expected, the estimated slope parameters for options/CDS portfolio returns are statistically different from zero and negative-valued in the full sample and in the 2008-2011 sub-sample. Estimated intercepts for the regression models that include options/CDS portfolio returns as a factor are statistically indistinguishable from zero both for the full sample and the 
2008-2011 sub-sample. Conversely, the estimated slope coefficients for the BKM portfolio returns are statistically insignificant regardless of the sample used. The estimated intercept parameter for the model containing the BKM portfolio returns as an independent variable is statistically different from zero at the $10 \%$ significance level only in the 2008-2011 subsample. These results support the visual evidence presented in Figure 3. The BKM portfolio returns are not significantly correlated with the momentum factor. Moreover, particularly during the global financial crisis and its immediate aftermath, BKM portfolio returns and other risk factors used in this testing exercise do not fully span the momentum factor. On the other hand, the momentum factor is fully spanned, regardless of the sample used, by the options/CDS portfolio returns and the additional risk factors.

Since the philosophy behind the construction of the momentum and options/CDS skewness portfolios are completely different, these findings cannot be attributed to data mining a serious concern in recent studies of factors aiming to explain the cross-sectional variations of stock returns (see Harvey, Liu, and Zhu, 2016). We discuss this issue in greater detail after presenting our time-series and cross-sectional evidence in support of our proposed method.

\subsection{Benefits of including CDS: Rationale for asset-pricing tests}

Thus far we have conducted a comparison of different skewness measures using the returns on portfolios based on each measure. We have shown that our parametric approach compares well to the established BKM method, and it outperforms BKM during times of high volatility. We now turn to evaluating the economic significance of the contribution of CDS to the computation of risk-neutral skewness.

As shown in Figure 3, the cumulative returns on the $\mathrm{SKEW}_{\text {opt } / C D S}$ and $\mathrm{SKEW}_{\text {opt }}$ portfolios are fairly close, with $\mathrm{SKEW}_{\text {opt } / C D S}$ outperforming $\mathrm{SKEW}_{\text {opt }}$ only slightly over the sample period. In order to evaluate the economic significance of the CDS contribution, however, one should not focus on the difference between $\mathrm{SKEW}_{\text {opt/CDS }}$ and $\mathrm{SKEW}_{\text {opt }}$. Rather, the focus should be on a portfolio that explicitly loads on the differences between the options/CDS and options-only skewness measures. By doing so, the dynamics of portfolio returns are driven specifically by skewness differences that arise from the inclusion of CDS. In tests that use 
portfolios based on skewness levels, the contribution of CDS is likely to be overshadowed by broad skewness-related dynamics.

We investigate whether differences between the options/CDS and options-only skewness give rise to a priced factor in the cross-section of stock returns. The battery of tests that we conduct revolve around a factor-mimicking portfolio that buys and sells stocks on the basis of differences between options/CDS and options-only risk-neutral skewness (henceforth, the DS factor). This factor is defined as the returns on a portfolio that buys (sells) the stocks in the top (bottom) $25 \%$ of the distribution of options/CDS and options-only skewness differences in month $t$-1. In unreported results, we define the DS factor using a top/bottom $10 \%$ cutoff, with similar conclusions. For each company, we discard the return on the first day of the month to avoid possible issues with non-synchronous trading between options, CDS, and stocks.

The cumulative return on the DS factor is shown in Figure 5, together with the cumulative return on the broad market factor of Fama and French (1993) (henceforth, MKT). As it is clear from the figure, the DS factor is distinct from the market factor. Figure 5 also shows the cumulative returns on a strategy that is long $\mathrm{SKEW}_{\text {opt } / C D S}$ and short $\mathrm{SKEW}_{\text {opt }}$. This strategy tracks the gap between the solid blue line and the dashed red line in Figure 3. The return profile on the difference between the skewness-based portfolios $\left(\mathrm{SKEW}_{\text {opt } / C D S}\right.$ and $\mathrm{SKEW}_{\text {opt }}$ ) and the DS factor confirms that, in order to evaluate the contribution of CDS to risk-neutral skewness, the trading strategy needs to focus explicitly on skewness differences as the sorting variable.

The advantage of an asset-pricing approach to evaluating the contribution of CDS to risk-neutral skewness is twofold. First, stocks are sorted into portfolios on the basis of potentially large values of skewness differences, but the regressions involve portfolio returns that do not exhibit the same large values. Second, there is a concern whether any large values of DS might be due to noise in the method used to extract risk-neutral distributions. If indeed this were the case, the portfolios would be based on an uninformative sorting, and we should find that the DS factor is not priced in the cross-section of stock returns. This insight is the key to interpreting our results and the value added from the empirical exercises 
that follow.

As mentioned in Section 4.1, we interpret our results in terms of moderate-jump risk. If DS were expressing the risk of jumps for the intermediate part of the distribution, a high (in absolute value) difference between options/CDS and options-only skewness should foreshadow a higher incidence of moderate-jump risk in the near future.

In the top charts of Figure 6, we show the fraction of intermediate-return variance that is explained by jumps across deciles of differences between options/CDS and options-only skewness. Variance $\left(\sigma^{2}\right)$ is the rolling sum of squared 15-minute returns between 9:30-16:00 daily in months $t+1$ to $t+3$. The non-jump component of variance $\left(\sigma_{n j}^{2}\right)$ is given by the MedRV estimator of Andersen, Dobrev, and Schaumburg (2012), and the fraction of variance due to jumps is $\phi=\frac{\sigma^{2}-\sigma_{n j}^{2}}{\sigma^{2}}$. The variance measures are computed using intermediate returns, that is returns between the $10^{t h}-40^{t h}$ and $60^{t h}-90^{t h}$ percentiles of the daily distribution of returns. We expect the fraction of intermediate-return variance explained by jumps to be higher when the absolute value of DS is larger. As a result, the fraction of variance explained by jumps should have a U-shaped pattern across DS deciles, which is what Figure 6 shows. ${ }^{10}$

We provide additional evidence that the DS factor is related to moderate-jump risk in Figure 7. We compute the change in the probability of intermediate returns under the options/CDS distribution relative to the options-only distribution, and we present the average (top chart) and the $90^{\text {th }}$ percentile (bottom chart) of this change in probabilities across DS deciles. ${ }^{11}$ If the DS factor expressed moderate-jump risk, the increase in intermediate-returns probabilities should be larger in the top and bottom DS deciles. As shown in Figure 7, this is the case. The probability of intermediate returns is, on average, slightly more than $2 \%$ higher

10 In unreported results (available upon request), we find that the U-shaped pattern is not present when considering the three months up to the DS formation period.

11 Intermediate returns are defined as those in the intervals $[-2 \sigma,-0.5 \sigma]$ and $[0.5 \sigma, 2 \sigma]$, where $\sigma$ is the volatility of the distribution. The probability of intermediate returns under the options/CDS distribution is $P_{\text {opt } / C D S}^{\text {int }}=P\left[r<2 \sigma_{\text {opt } / C D S}\right]-P\left[r<0.5 \sigma_{\text {opt } / C D S}\right]+P\left[r<-0.5 \sigma_{\text {opt } / C D S}\right]-P\left[r<-2 \sigma_{\text {opt } / C D S}\right]$, where $r$ indicates returns. The probability of intermediate returns under the options-only distribution $\left(P_{o p t}^{i n t}\right)$ is defined in a similar way, with $\sigma_{o p t}$ replacing $\sigma_{o p t / C D S}$. The increase in the probability of intermediate returns under the options/CDS distribution is defined as $\Delta P=\ln \frac{P_{o p t / C D S}^{\text {int }}}{P_{\text {opt }}^{i n t}}$. When computing the increase in the probability of intermediate positive returns, the interval we consider is $[0.5 \sigma, 2 \sigma]$. For the increase in the probability of intermediate negative returns, the interval is $[-2 \sigma,-0.5 \sigma]$. The DS deciles and the probability increases are as of month $t$. 
in the bottom DS decile, and about $1 \%$ higher in the top DS decile. At the $90^{\text {th }}$ percentile, the increase is more than $5 \%$ and about $3 \%$ in the bottom and top deciles, respectively.

The sign of the difference between options/CDS and options-only skewness indicates whether moderate jumps are likely to be positive or negative. As illustrated in Figure 8, a lower skewness translates into a shift of the probability mass to the right. This shift is also evident in Figure 2, which corresponds to a day when the options/CDS skewness is much more negative than the options-only skewness, hence the DS measure is large and negative. The options/CDS distribution indicates a higher likelihood of intermediate positive returns.

Figure 7 illustrates the relation between the sign of the DS measure and the sign of moderate jumps by showing the increase in the probability of (intermediate) positive and negative returns separately. To the extent that stocks in the top (bottom) DS decile are exposed to negative (positive) jump risk that is unspanned by options and CDS individually, the increase in the probability of intermediate returns should be more pronounced for negative (positive) returns in the top (bottom) DS decile. This is what we find.

The size of the effect is not particularly large but, together with the U-shaped pattern of the increase of intermediate-return probability across DS deciles, this evidence clearly supports our interpretation that DS expresses moderate-jump risk that is unspanned by options or CDS in isolation. Since the DS factor is long (short) stocks that are more likely to experience negative (positive) moderate jumps, the risk premium on DS should be positive. This is what we find in the tests we detail in Sections 4.4 and 4.5.

We provide additional details on the companies in the short and long legs of the DS factor. In Figure 9, we show two company characteristics, averaged by DS decile. DS is measured in month $t$, and the two characteristics are measured in the year preceding month t. The variables are realized daily volatility and average standardized earnings surprises (Chan, Jegadeesh, and Lakonishok, 1996, p. 1685). The variables exhibit the same U-shaped patterns across DS deciles that we found for the fraction of intermediate-return variance explained by jumps. Companies with high DS, in absolute value, have higher volatility and relatively low profitability. In the first and tenth deciles, realized volatility is about 5 percentage points higher than in the other deciles. This increase is noticeable but not extreme, 
consistent with the hypothesis that DS relates to moderate rather than large jumps. In line with the higher volatility, the profitability also indicates that these companies tend to grow less than the other firms in our sample.

Note that, while the companies in the top and bottom DS deciles have noticeably higher volatility and lower SUE than other companies in the sample, the variation across DS deciles is relatively small relative to sample variation. Specifically, realized volatility for high-DS companies is about 5 percentage points higher than for the other deciles and equal to about $37 \%$. Before averaging by DS decile, the sample median and $75 \%$ percentile volatilities are about $28 \%$ and $40 \%$, respectively. As for SUE, the averages in the first and tenth DS deciles are about 0 and -0.07 . Before averaging by DS decile, the sample median and the $25 \%$ percentile are about 0.25 and -0.29 . These figures confirm that the companies in the top and bottom DS deciles are only moderately riskier than those in the remainder of the sample, consistent with out interpretation that DS expresses the risk of moderate jumps.

Having established that the DS factor is related to moderate-jump risk, we now implement a series of time-series and cross-sectional tests to evaluate whether the DS factor commands a risk premium in the cross-section of stock returns.

\subsection{Benefits of including CDS: Time-series evidence}

The tests we conduct in this section focus on whether existing asset-pricing factors can explain the returns of the DS factor. In the context of asset pricing tests, the intercept of a time series regression represents a risk-adjusted average return, which can be interpreted as a risk premium. If the estimated intercept is statistically different from zero, then we conclude that the factors included in the time-series regression cannot fully account for the returns of the DS factor.

We fit the following regression model to the data:

$$
D S_{t}=\alpha+\sum_{i=1}^{N} \beta_{i} f_{t}^{i}+\varepsilon_{t}
$$

where $\alpha$ is the intercept (our parameter of interest), $f_{t}^{i}$ are the factors discussed below, and 
$\varepsilon_{t}$ is the error term. We report heteroscedasticity-consistent standard errors for all estimated parameters, following White (1980).

We use a large number of relevant asset-pricing factors, including the five Fama and French (2015) factors (the market, MKT, size, SMB, book-to-market, HML, profitability, RMW, and investment, CMA), the Carhart (1997) momentum factor (UMD) and Pastor and Stambaugh (2003) liquidity factor (LIQ). The long run and short run reversals factors, LT REV and ST REV respectively, capture the effect of past and recent stock performance on current stock returns (see, among others, Fama and French, 1996 and Novy-Marx, 2012, and references therein). $\triangle$ VIX and $\Delta \mathrm{VIX}^{2}$ are replicating portfolios for changes and squared changes in the implied volatility index VIX, VRP is the replicating portfolio for Bollerslev, Tauchen, and Zhou (2009)'s variance risk premium, and $\triangle \mathrm{CDX}_{H Y}$ is the changes in the spread of the CDX high-yield CDS index to control for aggregate default risk. ${ }^{12}$ We also include the $\mathrm{SKEW}_{\text {opt } / C D S}$ factor to ensure that the results are not driven by skewness.

The DS factor has a moderate positive correlation (0.27) with the market factor (MKT) and a negative correlation with $\triangle \operatorname{VIX}(-0.33)$, UMD (-0.38), and $\Delta \operatorname{CDX}_{H Y}(-0.38)$. The skewness factors $\mathrm{SKEW}_{\text {opt } / C D S}$ and $\mathrm{SKEW}_{\text {opt }}$ are highly correlated (0.99), though the correlation of DS with both $\mathrm{SKEW}_{\text {opt } / C D S}(0.52)$ and $\mathrm{SKEW}_{\text {opt }}$ (0.53) is only moderate. The BKMskewness factor $\mathrm{SKEW}_{B K M}$ is weakly correlated with DS (0.28) and moderately correlated with $\mathrm{SKEW}_{\text {opt } / C D S}(0.52)$ and $\mathrm{SKEW}_{\text {opt }}(0.53)$.

We report the time series test results in Tables 8 (for the full sample) and 9 (for 2008 to 2011). The first column of Table 8 shows that, when using a small set of factors that includes MKT, SMB, HML, UMD, LIQ, and $\triangle \mathrm{VIX}_{\text {repl }}$, the intercept - the risk adjusted average return - is about $0.3 \%$ per month and is statistically significant at the $10 \%$ level. The intercept remains about the same as we include progressively more factors, and the statistical significance improves to the $5 \%$ level. The inclusion of the $\mathrm{SKEW}_{\text {opt } / C D S}$ factor improves the adjusted $\mathrm{R}^{2}$ from $39 \%$ to $44 \%$. When we substitute the factor with $\mathrm{SKEW}_{B K M}$,

12 The replicating portfolio for VIX changes is described in footnote 9. The replicating portfolios for squared VIX changes and for the variance risk premium are built in exactly the same manner. The only difference is that stocks are sorted into portfolios using the coefficients on squared VIX changes and on the variance risk premium, respectively, rather than on VIX changes. 
the $\mathrm{R}^{2}$ declines back to $39 \%$. A pertinent question is which leg of the DS portfolio is delivering the results. In columns (6) and (7) of Table 8, we regress the returns of the long leg and of the short leg, respectively, on the full set of factors. We observe the following. First, the risk-adjusted average return of the DS portfolio is driven by the long leg. Second, both legs load heavily on the MKT factor, which results in high adjusted $\mathrm{R}^{2}$ s. Finally, both legs are highly correlated with $\Delta \mathrm{VIX}_{\text {repl }}^{2}$ and the $\mathrm{SKEW}_{\text {opt } / C D S}$ factor.

In Table 9, we restrict our sample to the 2008-2011 period. Focusing on this period of heightened financial uncertainty, we find that the risk-adjusted average return is noticeably higher, ranging between $0.8 \%$ to $1.1 \%$ per month. The statistical significance is about the same or stronger, with the exception of the specification with the smallest set of risk factors. While larger, the adjusted $\mathrm{R}^{2}$ pattern is similar to what we observed in Table 8 . In contrast to what we observe in the previous table, columns (6) and (7) imply that the short leg is driving the results. CDS spreads are informative about default risk during times of financial stress.

Our estimates of the risk-adjusted average returns for the DS factor are comparable with the expected skewness premium estimates of Rehman and Vilkov (2012) and Stilger, Kostakis, and Poon (2017) . Both studies find positive skewness premia in the neighborhood of $0.5 \%$ per month.

Finally, we would like to emphasize that the returns on the DS portfolio are gross of transaction costs, and shorting fees might be elevated for risky stocks, especially at times of market stress. As such, the estimated risk premia should be considered an upper bound to the actual risk premium. However, we should also emphasize that our asset pricing tests are meant to evaluate whether combining option prices and CDS spreads provides additional information relative to the standard methods for extracting risk-neutral distributions for individual stocks. The presence of transaction costs does not detract from our finding that combining options and CDS spreads does provide information about the cross-section of stocks. Transaction costs affect whether one can profitably trade on the information.

In this section, we examined the economic significance of the DS factor through the lens of time-series asset pricing tests. Our findings show that the standard factors do not fully 
account for the DS factor, since the estimates for the intercept are statistically significant.

\subsection{Benefits of including CDS: Cross-sectional evidence}

In this section, we carry out a second set of tests where we use the two-stage method of Fama and MacBeth (1973). This method allows us to introduce stock-level characteristics. Including characteristics in asset-pricing tests is crucial, since they can proxy for risk exposure (see, for instance, Daniel and Titman, 1997 and Daniel, Titman, and Wei, 2001).

The first stage of the Fama and MacBeth (1973) procedure estimates the sensitivity of the portfolio returns to the factors with a series of portfolio-specific time-series regressions:

$$
r_{t}^{j}-r_{t}^{f}=\alpha_{j}+\sum_{i=1}^{N} \beta_{i}^{j} f_{t}^{i}+\varepsilon_{t}^{j}, \forall j
$$

where $r_{t}^{j}$ is the return on portfolio $j, r_{t}^{f}$ is the risk-free rate, and $f_{t}^{i}$ is one of the $N$ factors included. We consider 35 portfolios: 10 decile portfolios based on the distributions of DS in month $t$-1, and the replication of the 25 size/book-to-market portfolios of Fama and French (1993) using stocks for which we can calculate the volatility spreads of Bali and Hovakimian (2009) and the implied-volatility smirk of Xing, Zhang, and Zhao (2010).

The second step of the Fama and MacBeth (1973) methodology uses cross-sectional regressions to evaluate how differences in the estimated factor loadings explain excess returns:

$$
r_{t}^{j}-r_{t}^{f}=\lambda_{t}^{0}+\sum_{i=1}^{N} \lambda_{t}^{i} \hat{\beta}_{i}^{j}+\sum_{k=1}^{K} \phi_{k} \gamma_{t-1, k}^{j}+\epsilon_{j}, \forall t
$$

where $\lambda_{t}^{0}$ is the pricing error at time $t, \lambda_{t}^{i}$ is the risk premium on factor $i$ at time $t, \hat{\beta}_{t}^{j}$ are the estimates from the first step, $\gamma_{t-1, k}^{j}$ is characteristic $k$ for portfolio $j$ as of time $t-1$ (calculated as the average of stock-level characteristics), and $\phi_{k}$ is the regression coefficient for characteristic $\gamma_{t-1, k}^{j}$. The risk premium on factor $f_{t}^{i}$ is computed as the average of the coefficients from the $T$ cross-sectional regressions, and its statistical significance is assessed 
with Shanken (1992)-adjusted standard errors:

$$
\hat{\lambda}^{i}=\frac{1}{T} \sum_{t=1}^{T} \hat{\lambda}_{t}^{i} .
$$

The characteristics we consider are related to higher-moment risks in stock and option returns, and have been shown to explain the cross sections of equity and option returns: idiosyncratic volatility (Ang, Hodrick, Xing, and Zhang, 2006), volatility spreads (Bali and Hovakimian, 2009), the implied-volatility smirk of Xing, Zhang, and Zhao (2010), the changes in call and put implied volatility of An, Ang, Bali, and Cakici (2014), and the tail covariance between stock market returns and company-specific returns introduced by Bali, Cakici, and Whitelaw (2014). In addition, we include the 5-year CDS spread to evaluate whether the contribution of the DS factor to the cross-section of returns is explained by default risk.

In the Fama-MacBeth procedure, the risk premia are identified from cross-sectional variations in factor sensitivities, and our cross section includes 35 portfolios. As such, each specification we discuss includes only a subset of the factors we use in the time series tests, and we study various combinations of factors and characteristics to ensure that our findings are robust. We present the first set of results in Table 10, where we keep the factors constant, but change the set of characteristics included in the regression. In the full sample, the risk premium on DS is statistically significant at the $5 \%$ level and equal to $0.5 \%$ per month. It is comparable to the intercept in the time-series regressions of DS on other factors. ${ }^{13}$ In line with Ang, Hodrick, Xing, and Zhang (2006), we find that stocks with high idiosyncratic volatility have lower returns. In addition, controlling for skewness using either $\mathrm{SKEW}_{\text {opt/cds }}$ or $\mathrm{SKEW}_{B K M}$ factors does not affect our findings. In the 2008-2011 sub-sample, DS factor commands a higher premium, around $1 \%$ per month, which is in line with our time-series findings. We find that the estimated coefficients for $\Delta$ cvol and $\Delta$ pvol (changes in call or put implied volatilities) have the same signs as in An, Ang, Bali, and Cakici (2014) and are

13 The risk premia on most factors are statistically not different from zero. This is not surprising, since the test portfolios we use are designed to generate cross-sectional dispersion in risk sensitivity to the DS factor. Hence the test is designed to capture whether the risk premium on the DS factor is absorbed by other factors. The 25 Fama-French portfolios are meant to generate cross-sectional sensitivity to SMB and HML factors. However, since the mean returns to these two factors are statistically not different from zero over the sample period, we do not expect to observe a risk premium for either factor. 
statistically significant in several instances during this period.

Studies such as Acharya and Johnson (2007), Ni and Pan (2011), and Han and Zhou (2011) indicate the presence of information flows from the CDS market to the equity market. Our results about the DS factor are unlikely to be driven by such flows. We include CDS spreads in our cross-sectional regression and do not observe a statistically significant coefficient for the spreads. Moreover, we skip the first return of the month in building the test portfolios, which eliminates the observation most likely affected by the delayed information flow.

In Table 11 we keep the set of characteristics constant and change the factors. We use either the three or the five Fama-French factors; see Fama and French (1993, 2015). In both the full sample and in the 2008-2011 sub-sample, the estimated DS risk premium remains comparable to the values reported in Table 10. In model (3), the estimated DS premium is statistically zero. However, the asset pricing test is rejected for model (3), since the estimated pricing error is significantly different from zero.

The cross-sectional evidence presented in this section corroborate the time-series evidence reported in Section 4.4. In addition, our cross-sectional results demonstrate robustness of DS premia to the inclusion of stock characteristics in asset pricing tests.

\subsection{Robustness}

We evaluate the sensitivity of our findings to changes in default thresholds and to two additional CDS tenors. We report these results in Table 12. So far, we have presented empirical evidence based on the thresholds shown in Panel A, Table 4. In columns 1 to 6 of Table 12, we report results based on the default thresholds shown in Panel B, Table 4. The estimated time-series intercepts are slightly smaller than those reported in Tables 8 and 9. When compared with the findings presented in Sections 4.4 and 4.5, these results highlight the importance of choosing default thresholds based on company characteristics, such as size and leverage. The intercepts for $120 \%$ of the mean for $2008-2011$ sub-sample and $80 \%$ of the mean in the full sample are statistically significant, and most of the remaining marginally fail 
the statistical significance test. The adjusted $\mathrm{R}^{2} \mathrm{~S}$ are comparable to our previously reported values. The size of the DS risk premium is similar to those shown in Tables 10 and 11 in both full sample and in the 2008-2011 sub-sample.

As noted by Chen, Fleming, Jackson, Li, and Sarkar (2011), trading liquidity in the CDS market is concentrated in the five-year tenor. Therefore, we focus on risk-neutral distributions extracted using options and the appropriately compounded five-year CDS spread, even though the horizon to which the distribution refers is three months. Even if five-year spreads are the most liquid and thus more likely to have a higher signal-to-noise ratio, Friewald, Wagner, and Zechner (2014) find that the term-structure of CDS spreads is informative about the equity risk premium. We repeat our analysis using either one-year CDS spreads from Markit or three-month CDS spreads, obtained by linearly extrapolating log-CDS spreads with maturities between six months and 10 years. The last four columns of Table 12 show that the results are robust to using alternative CDS tenors. In both time-series and crosssectional regressions, the size of the estimated intercepts and DS premia are comparable to our reported results. The estimated intercepts have larger $t$ statistics compared with those reported in Tables 8 and 9. In Fama-MacBeth regressions, we slightly lower $t$ statistics for the DS premia.

Harvey, Liu, and Zhu (2016) document the pervasive presence of data mining in many cross-sectional results in the asset pricing literature. They recommend setting a higher bar for asset-pricing tests evaluating cross-sectional factors, a $t$ statistics in excess of 3 , translating into statistical significance between $97.5 \%$ and $99 \%$ for cross-sectional tests with four factors. Increasing the number of factors implies far more stringent significance criteria. However, they limit their recommendation to new and purely empirical results. They explicitly state that micro-founded, theoretically-motivated results need not pass their proposed bar.

In this study, we contribute to a mature literature. The link between skewness and equity returns is empirically and theoretically well established. There are a number of papers - we have cited Rehman and Vilkov (2012), Conrad, Dittmar, and Ghysels (2013), and Stilger, Kostakis, and Poon (2017), among others - that specifically investigate the link between riskneutral, firm-specific skewness and the cross-section of returns. In addition, studies such as 
Chabi-Yo, Leisen, and Renault (2014), Feunou, Jahan-Parvar, and Tédongap (2013), and Feunou, Jahan-Parvar, and Okou (Forthcoming) explicitly derive equilibrium asset pricing models for skewness preferences. ${ }^{14}$ As such, we contribute to a clearly theoretically-founded line of research.

In addition, the relation between the momentum strategy returns and the options/CDS portfolio returns discussed in Section 4.2 is relevant to address Harvey, Liu, and Zhu (2016) concerns. The evidence we find on the relation between momentum and skewness returns is incidental to the central topic of our work, yet it fits naturally in the overall discussion. It is unlikely that both our main difference-in-skewness results and the link between momentum and skewness returns are the outcome of data mining.

\section{Conclusions}

We develop a new method to extract the risk-neutral distribution of firm-specific expected stock returns. Traditionally, risk neutral distributions are based on option prices. In the case of stock indexes, like the S\&P 500, the number of actively traded options with out-ofthe-money strikes is large enough that risk-neutral distributions are informative about tail risk. For individual companies, however, only options with strike price close to the current stock price are actively traded. Our method combines options and credit default swaps (CDS) to extract risk-neutral distributions. By construction, the options/CDS-implied riskneutral distributions reflect the default risk embedded in CDS spreads. In addition, the combination of options and CDS is also informative about the intermediate part of the riskneutral distribution. This part of the distribution is influenced by moderate-sized, signed jumps. Options and CDS individually offer limited information about expected moderatesized jumps. Jointly, however, options and CDS help us span this part of a risk-neutral distribution by providing a more informative skewness measure.

We evaluate our method with a series of asset pricing tests that revolve around a factor that buys (sells) stocks with large differences between options/CDS and options-only

14 Guidolin and Timmermann (2008) contribute to this literature in an international, multi-country context. 
skewness. This factor is long (short) in stocks exposed to negative (positive) moderate-sized jump risk that is unspanned by options and CDS individually. After controlling for a large set of asset pricing factors and stock characteristics, we find that the factor commands a risk premium of $0.5 \%$ per month. While the results are robust to different assumptions about key inputs of the method, we find that it is important to choose default thresholds that reflect the size and leverage of a company. 


\section{References}

Acharya, V., and T. Johnson, 2007, "Insider trading in credit derivatives," Journal of Financial Economics, 84(1), 110-141.

Aït-Sahalia, Y., and A. Lo, 1998, "Nonparametric estimation of state-price densities implicit in financial asset prices," Journal of Finance, 53(2), 499-547.

Amaya, D., P. Christoffersen, K. Jacobs, and A. Vasquez, 2015, "Does realized skewness predict the cross-section of equity returns?," Journal of Financial Economics, 118(1), 135167.

An, B.-J., A. Ang, T. Bali, and N. Cakici, 2014, "The joint cross section of stocks and options," Journal of Finance, 69(5), 2279-2337.

Andersen, T., D. Dobrev, and E. Schaumburg, 2012, "Jump-robust volatility estimation using nearest neighbor truncation," Journal of Econometrics, 169(1), 75-93.

Andersen, T., N. Fusari, and V. Todorov, 2015, "Parametric inference and dynamic state recovery from option panels," Econometrica, 83(3), 1081-1145.

Ang, A., R. Hodrick, Y. Xing, and X. Zhang, 2006, "The cross-section of volatility and expected returns," Journal of Finance, 61(1), 259-299.

Arora, N., P. Ghandi, and F. Longstaff, 2012, "Counterparty credit risk and the credit default swap market," Journal of Financial Economics, 103(2), 280-293.

Bakshi, G., N. Kapadia, and D. Madan, 2003, "Stock return characteristics, skew laws, and the differential pricing of individual equity options," Review of Financial Studies, 16(1), $101-143$.

Bakshi, G., and D. Madan, 2000, "Spanning and derivative-security valuation," Journal of Financial Economics, 55(2), 205-238.

Bali, T., N. Cakici, and R. Whitelaw, 2014, "Hybrid tail risk and expected stock returns: When does the tail wag the dog?," Review of Asset Pricing Studies, 4(2), 206-246.

Bali, T., and A. Hovakimian, 2009, "Volatility spreads and expected stock returns," Management Science, 55(11), 1797-1812.

Bali, T., and S. Murray, 2013, "Does risk-neutral skewness predict the cross-section of equity option portfolio returns?," Journal of Financial and Quantitative Analysis, 48(4), 1145-1171.

Bandi, F., and R. Renò, 2016, "Price and volatility co-jumps," Journal of Financial Economics, 119(1), 107-146.

Barroso, P., and P. Santa-Clara, 2015, "Momentum has its moments," Journal of Financial Economics, 116(1), 111-120. 
Bates, D., 1991, "The crash of '87: was it expected? The evidence from options markets," Journal of Finance, 46(3), 1009-1044.

— , 2000, "Post-' 87 crash fears in the S\&P 500 futures option market," Journal of Financial Economics, 94(1-2), 181-238.

Birru, J., and S. Figlewski, 2012, "Anatomy of a meltdown: The risk neutral density for the S\&P 500 in the fall of 2008," Journal of Financial Markets, 15(2), 151-180.

Bliss, R., and N. Panigirtzoglou, 2002, "Testing the stability of implied probability density functions," Journal of Banking \& Finance, 26(2-3), 381-422.

Bollerslev, T., G. Tauchen, and H. Zhou, 2009, "Expected stock returns and variance risk premia," Review of Financial Studies, 22(11), 4463-4492.

Breeden, D., and R. Litzenberger, 1978, "Prices of state-contingent claims implicit in option prices," Journal of Business, 51(4), 621-651.

Broadie, M., M. Chernov, and M. Johannes, 2007, "Model specification and risk premia: Evidence from futures options," Journal of Finance, 62(3), 1453-1490.

Cao, C., F. Yu, and Z. Zhong, 2010, "The information content of option-implied volatility for credit default swap valuation," Journal of Financial Markets, 13(3), 321-343.

Carey, M., and M. Gordy, 2016, "The bank as grim reaper: Debt composition and recoveries on defaulted debt," Finance and Economics Discussion Series, Federal Reserve Board.

Carhart, M., 1997, "On persistence in mutual fund performance," Journal of Finance, 52(1), $57-82$.

Carr, P., and L. Wu, 2010, "Stock options and credit default swaps: A joint framework for valuation and estimation," Journal of Financial Econometrics, 8(4), 409-449.

— , 2011, "A simple robust link between American puts and credit protection," Review of Financial Studies, 24(2), 473-505.

Chabi-Yo, F., D. P. Leisen, and E. Renault, 2014, "Aggregation of preferences for skewed asset returns," Journal of Economic Theory, 154, 453 - 489.

Chan, L., N. Jegadeesh, and J. Lakonishok, 1996, "Momentum strategies," Journal of Finance, 51(5), 1681-1713.

Chen, K., M. Fleming, J. Jackson, A. Li, and A. Sarkar, 2011, "An analysis of CDS transactions: Implications for public reporting," FRB of New York Staff Report No. $51 \%$.

Colacito, R., E. Ghysels, J. Meng, and W. Siwasarit, 2016, "Skewness in expected macro fundamentals and the predictability of equity returns: evidence and theory," Review of Financial Studies, 29(8), 2069-2109. 
Conrad, J., R. Dittmar, and E. Ghysels, 2013, "Ex ante skewness and expected stock returns," Journal of Finance, 68(1), 85-124.

Cox, J., S. Ross, and M. Rubinstein, 1979, "Option pricing: A simplified approach," Journal of Financial Economics, 7(3), 229-263.

Cremers, M., J. Driessen, and P. Maenhout, 2008, "Explaining the level of credit spreads: Option-implied jump risk premia in a firm value model," Review of Financial Studies, 21(5), 2209-2242.

Cremers, M., J. Driessen, P. Maenhout, and D. Weinbaum, 2008, "Individual stock-option prices and credit spreads," Journal of Banking $\&$ Finance, 32(12), 2706-2715.

Daniel, K., and T. Moskowitz, 2016, "Momentum crashes," Journal of Financial Economics, $122(2), 221-247$.

Daniel, K., and S. Titman, 1997, "Evidence on the characteristics of cross sectional variation in stock returns," Journal of Finance, 52(1), 1-33.

Daniel, K., S. Titman, and K. Wei, 2001, "Explaining the cross-section of stock returns in Japan: Factors or characteristics," Journal of Finance, 56(2), 743-766.

DeMiguel, V., Y. Plyakha, R. Uppal, and G. Vilkov, 2013, "Improving portfolio selection using option-implied volatility and skewness," Journal of Financial and Quantitative Analysis, 48(6), 1813-1845.

Dennis, P., and S. Mayhew, 2002, "Risk-neutral skewness: Evidence from stock options," Journal of Financial and Quantitative Analysis, 37(3), 471-493.

Driessen, J., P. Maenhout, and G. Vilkov, 2009, "The price of correlation risk: Evidence from equity options," Journal of Finance, 64(3), 1377-1406.

Duffie, D. Singleton, K., 2003, Credit risk: Pricing, measurement, and management. Princeton University Press, Princeton, N.J., 1 edn.

Fama, E., and K. French, 1993, "Common risk factors in the returns on stocks and bonds," Journal of Financial Economics, 33(1), 3-56.

— , 1996, "Multifactor explanations of asset pricing anomalies," Journal of Finance, $51(1), 55-84$.

— , 2015, "A five-factor asset pricing model," Journal of Financial Economics, 116(1), $1-22$.

Fama, E., and J. MacBeth, 1973, "Risk, return, and equilibrium: Empirical tests," Journal of Political Economy, 81(3), 607-636.

Fan, H., and S. Sundaresan, 2000, "Debt valuation, renegotiation, and optimal dividend policy," Review of Financial Studies, 13(4), 1057-1099. 
Feunou, B., M. Jahan-Parvar, and C. Okou, Forthcoming, "Downside variance risk premium," Journal of Financial Econometrics.

Feunou, B., M. Jahan-Parvar, and R. Tédongap, 2013, "Modeling market downside volatility," Review of Finance, 17(1), 443-481.

— , 2016, "Which parametric model for conditional skewness?," European Journal of Finance, 22(13), 1237-1271.

Figlewski, S., 2010, "Estimating the implied risk-neutral density for the US market portfolio," in "Volatility and time series econometrics: essays in honor of Robert Engle", edited by T. Bollerslev, J. Russell, and M.Watson. Oxford University Press.

Friewald, N., C. Wagner, and J. Zechner, 2014, "The cross-section of credit risk premia and equity returns," Journal of Finance, 69(6), 2419-2469.

Gârleanu, N., L. Pedersen, and A. Poteshman, 2009, "Demand-based option pricing," Review of Financial Studies, 22(10), 4259-4299.

Ghysels, E., A. Plazzi, and R. Valkanov, 2016, "Why invest in emerging markets? The role of conditional return asymmetry," Journal of Finance, 71(5), 2145-2192.

Guidolin, M., and A. Timmermann, 2008, "International asset allocation under regime switching, skew, and kurtosis preferences," Review of Financial Studies, 21(2), 889-935.

Han, B., and Y. Zhou, 2011, "Term structure of credit default spreads and cross-section of stock returns," Working paper.

Hansen, B., 1994, "Autoregressive conditional density estimation," International Economic Review, 35(3), 705-730.

Harvey, C., Y. Liu, and H. Zhu, 2016, "... and the cross-section of expected returns," Review of Financial Studies, 29(1), 5-68.

Harvey, C., and A. Siddique, 2000, "Conditional skewness in asset pricing tests," Journal of Finance, 55, 1263-1295.

Jackwerth, J., and M. Rubinstein, 1996, "Recovering probability distributions from option prices," Journal of Finance, 51(5), 1611-1631.

JPMorgan, 2001, "Par credit default swap spread approximation from default probabilities," JPMorgan Securities Inc. Report.

Khozan, R., A. Neuberger, and P. Schneider, 2013, "The skew risk premium in the equity index market," Review of Financial Studies, 26(9), 2174-2203.

Kim, T., and H. White, 2004, "On more robust estimation of skewness and kurtosis," Finance Research Letters, 1(1), 56-73. 
Longstaff, F., 1995, "Option pricing and the martingale restriction," Review of Financial Studies, 8(4), 1091-1124.

Madan, D., and F. Milne, 1994, "Contingent claims valued and hedged by pricing and investing in a basis," Mathematical Finance, 4(3), 223-245.

Neuberger, A., 2012, "Realized skewness," Review of Financial Studies, 25(11), 3423-3455.

Ni, S., and J. Pan, 2011, "Trading puts and CDS on stocks with short sale ban," Working paper.

Novy-Marx, R., 2012, "Is momentum really momentum?," Journal of Financial Economics, 103(3), 429-453.

Pastor, L., and R. Stambaugh, 2003, "Liquidity risk and expected stock returns," Journal of Political Economy, 111(3), 642-685.

Patton, A., 2004, "On the out-of-sample importance of skewness and asymmetric dependence for asset allocation," Journal of Financial Econometrics, 2(1), 130-168.

Patton, A., and K. Sheppard, 2015, "Good volatility, bad volatility: Signed jumps and the persistence of volatility," Review of Economics and Statistics, 97(3), 683-697.

Rehman, Z., and G. Vilkov, 2012, "Risk-neutral skewness: Return predictability and its sources," Working paper, Frankfurt University.

Rubinstein, M., 1994, "Implied binomial trees," Journal of Finance, 49(3), 771-818.

Santa-Clara, P., and A. Saretto, 2009, "Option strategies: Good deals and margin calls," Journal of Financial Markets, 12(3), 391-417.

Shanken, J., 1992, "On the estimation of beta-pricing models," Review of Financial Studies.

Shimko, D., 1993, "Bounds of probability," Risk, 6, 33-37.

Stilger, P., A. Kostakis, and S. Poon, 2017, "What does risk-neutral skewness tell us about future stock returns?," Management Science, 63(6), 1814-1834.

White, H., 1980, "A heteroskedasticity-consistent covariance matrix estimator and a direct test for heteroskedasticity," Econometrica, 48(4), 817-838.

Xing, Y., X. Zhang, and R. Zhao, 2010, "What does the individual option volatility smirk tell us about future equity returns?," Journal of Financial and Quantitative Analysis, 45(3), 641-662.

Zhang, B., H. Zhou, and H. Zhu, 2009, "Explaining credit default swap spreads with the equity volatility and jump risks of individual firms," Review of Financial Studies, 22(12), 5099-5131. 


\section{Figure 1: The contribution of options and CDS to risk-neutral return distributions}

The figure provides a stylized illustration of the contribution that options and CDS give to the risk-neutral distribution of returns. The cumulative probabilities extracted from option prices (Section 3.1) drive the central part of the distribution. The red markers correspond to traded strikes, which are normally clustered close to the current stock price. The location of the markers on the density function indicates which part of the distribution each option is informative about. The CDS-implied default probability (Section 3.2) drives the distribution up to the default threshold (Section 3.3).

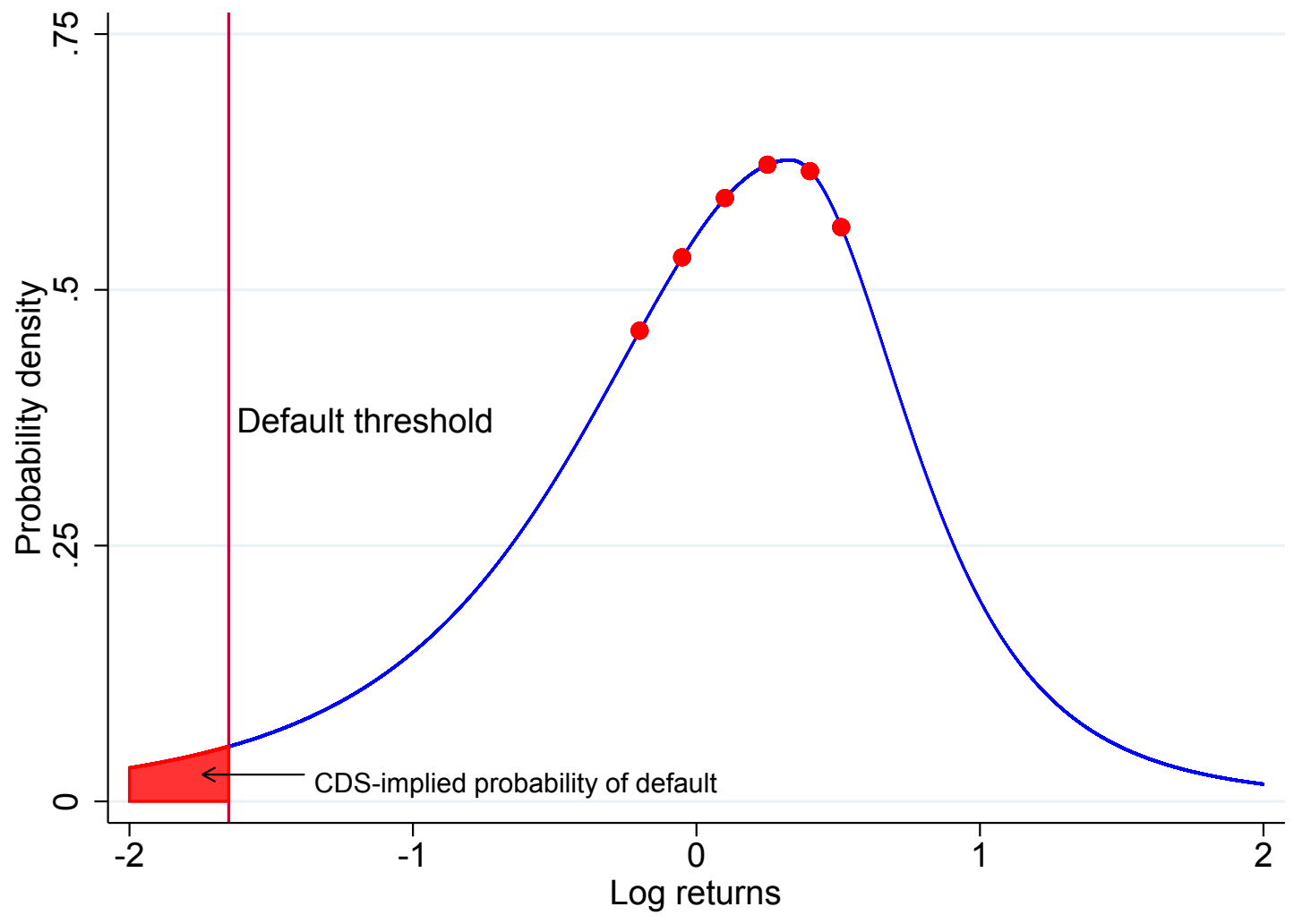


Figure 2: Example of risk neutral density estimated with and without CDS

The top chart shows the risk-neutral distribution of returns for Citigroup Inc. on July 20, 2009. The distribution in solid red is estimated using options and CDS, while the one based on options only is in dashed blue. On the same day and for the same company, the bottom chart shows the probability density of the options/CDS distribution when this probability density is higher than the probability density of the options-only distribution.
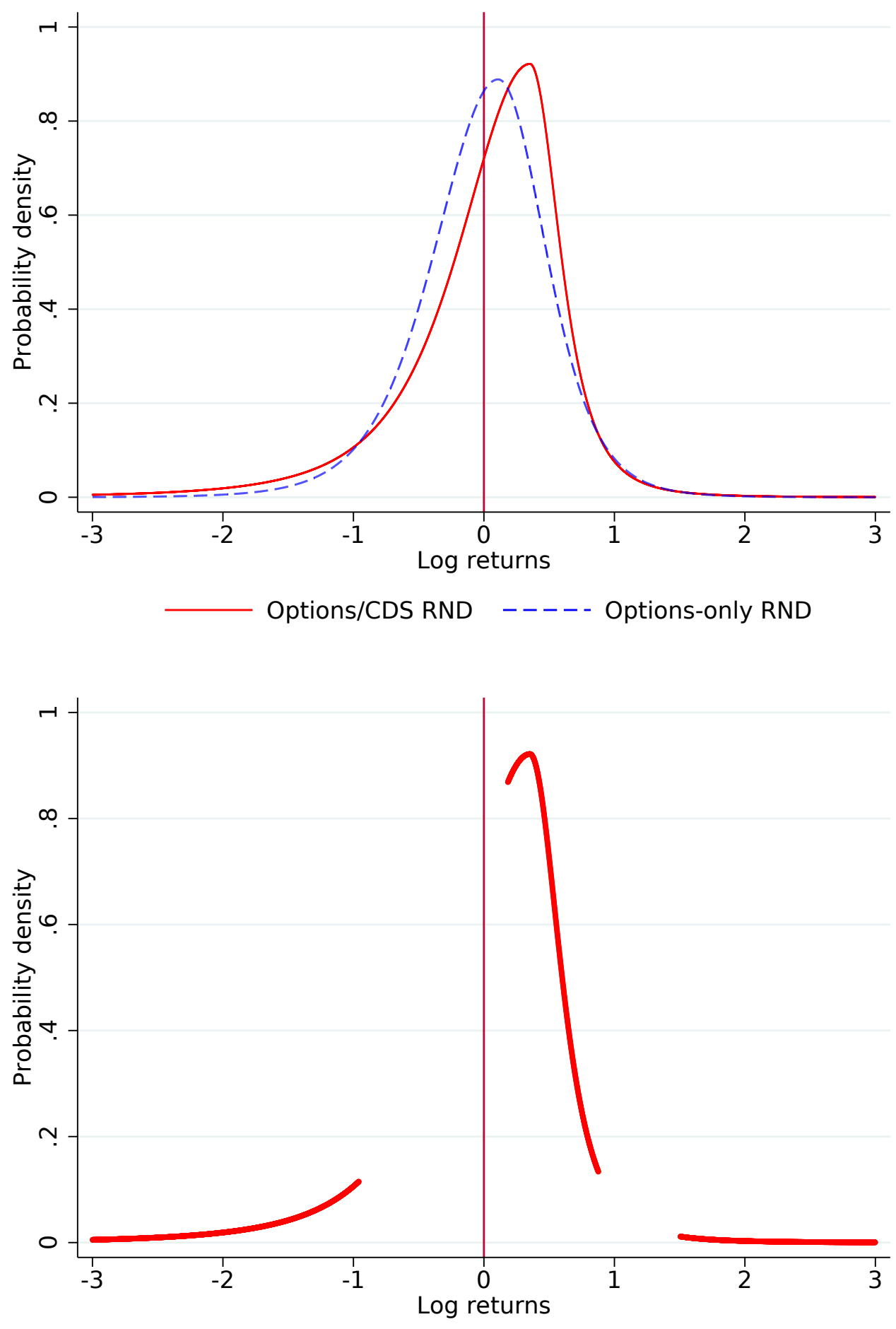
Figure 3: Cumulative returns of momentum and skewness-related factors

The solid blue line is the return on the portfolio based on options/CDS-skewness $\left(\mathrm{SKEW}_{\text {opt } / C D S}\right)$. The portfolio is long stocks in the top $25 \%$ of the distribution of average skewness in month $t-1$ and short those in the bottom $25 \%$. The dashed red line is the return on the portfolio based on options-only skewness $\left(\mathrm{SKEW}_{\text {opt }}\right)$. The black dash-dot line is the return on a third skewness-based portfolio, with skewness computed according to the Bakshi, Kapadia, and Madan (2003) methodology $\left(\mathrm{SKEW}_{B K M}\right)$. The grey solid thick line is the return on the UMD momentum factor. The shaded are shows the December 2007-June 2009 recession. The sample includes February 2006 to December 2015.

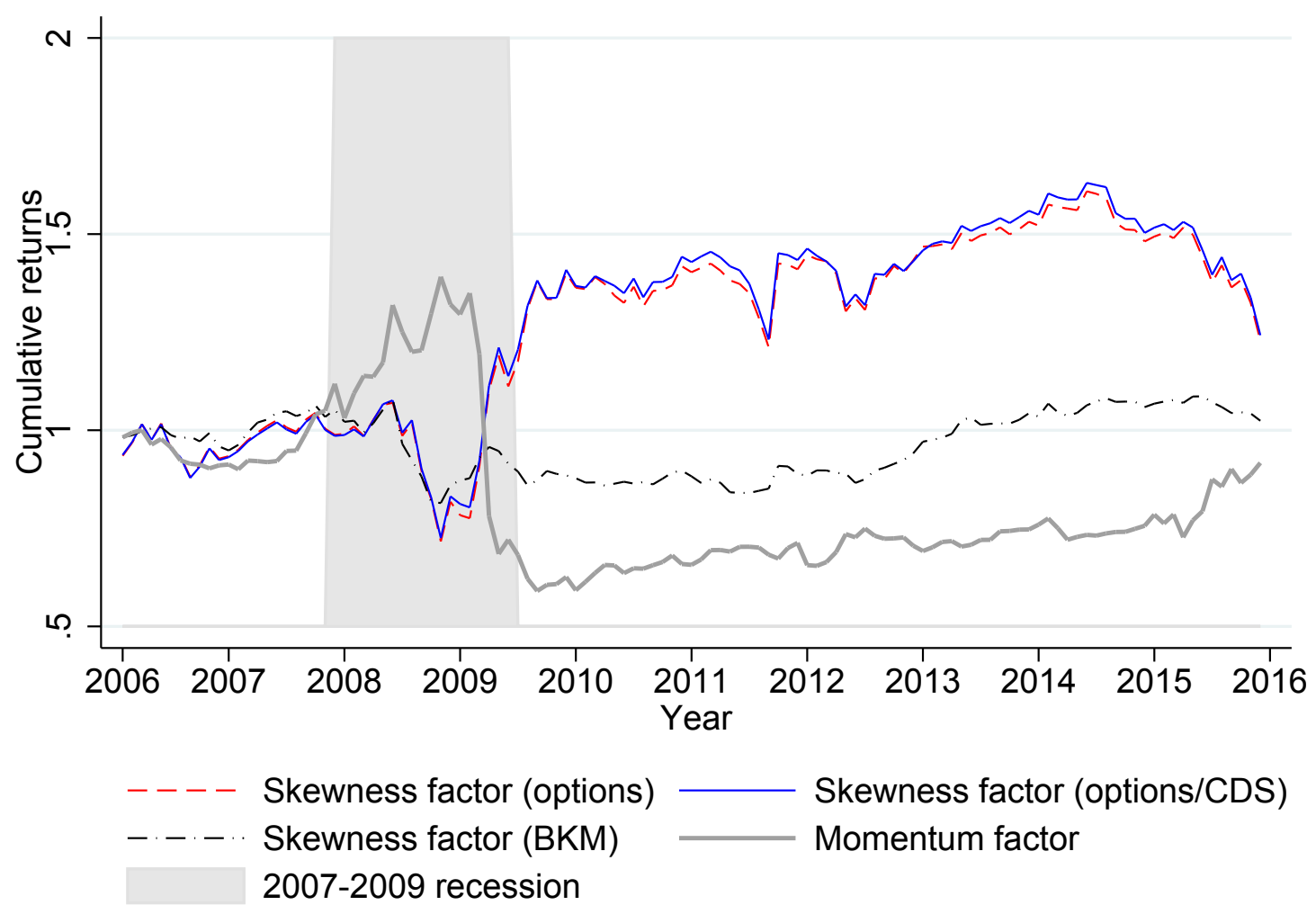




\section{Figure 4: Covariation of the momentum and skewness portfolios}

The top chart is a scatter plot of the monthly returns on the UMD momentum portfolio and of the returns on the options/CDS skewness-based portfolio. The portfolio is long stocks in the top $25 \%$ of the distribution of average skewness in month $t-1$ and short those in the bottom $25 \%$. In the bottom chart, the skewness is calculated according to the Bakshi, Kapadia, and Madan (2003) methodology. In both charts, linear fit lines are shown in solid red. The vertical dashed lines center the plots on zero returns for the skewness portfolios. Solid blue markers correspond to 2009, with months as labels. The sample covers February 2006 to December 2015 .
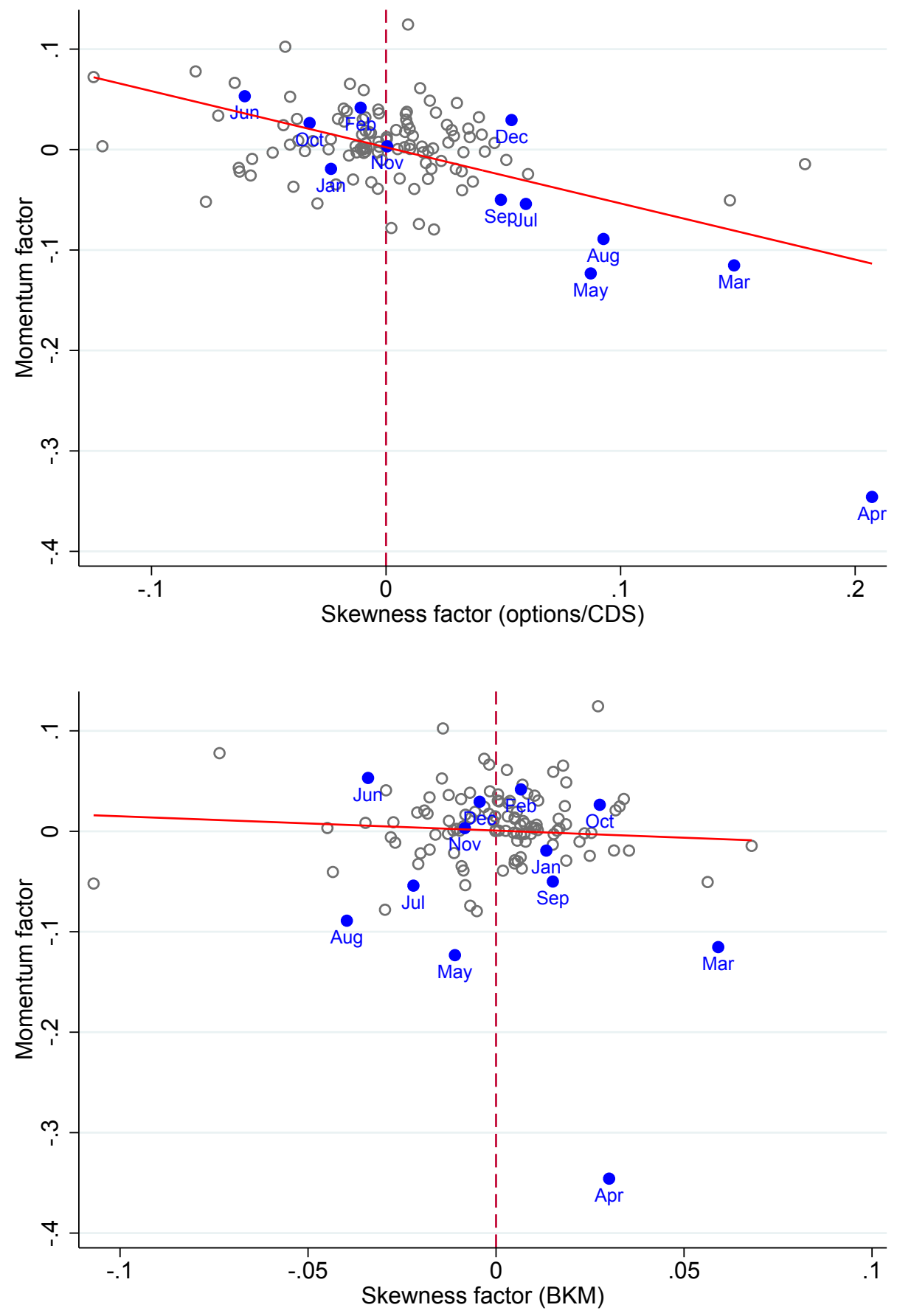


\section{Figure 5: DS factor and market factor, cumulative returns}

The difference-in-skewness (DS) factor is a long/short portfolio that, in month $t$, buys (sells) stocks in the top (bottom) $25 \%$ of the month $t-1$ distribution of skewness differences between the options/CDS- and optionsonly distributions. End-of-month values for skewness are the average of the last three daily observations within each month. The market factor is the return of the Fama-French market portfolio (Fama and French, 1993) over the risk-free rate. Cumulative returns for the DS factor are shown in solid red, and cumulative returns for the market factor are in dashed blue. The dash-dot black line shows the cumulative returns for a trading strategy that buys the portfolio based on options/CDS-skewness and sells the portfolio based on options-only skewness. The sample includes February 2006 to December 2015.

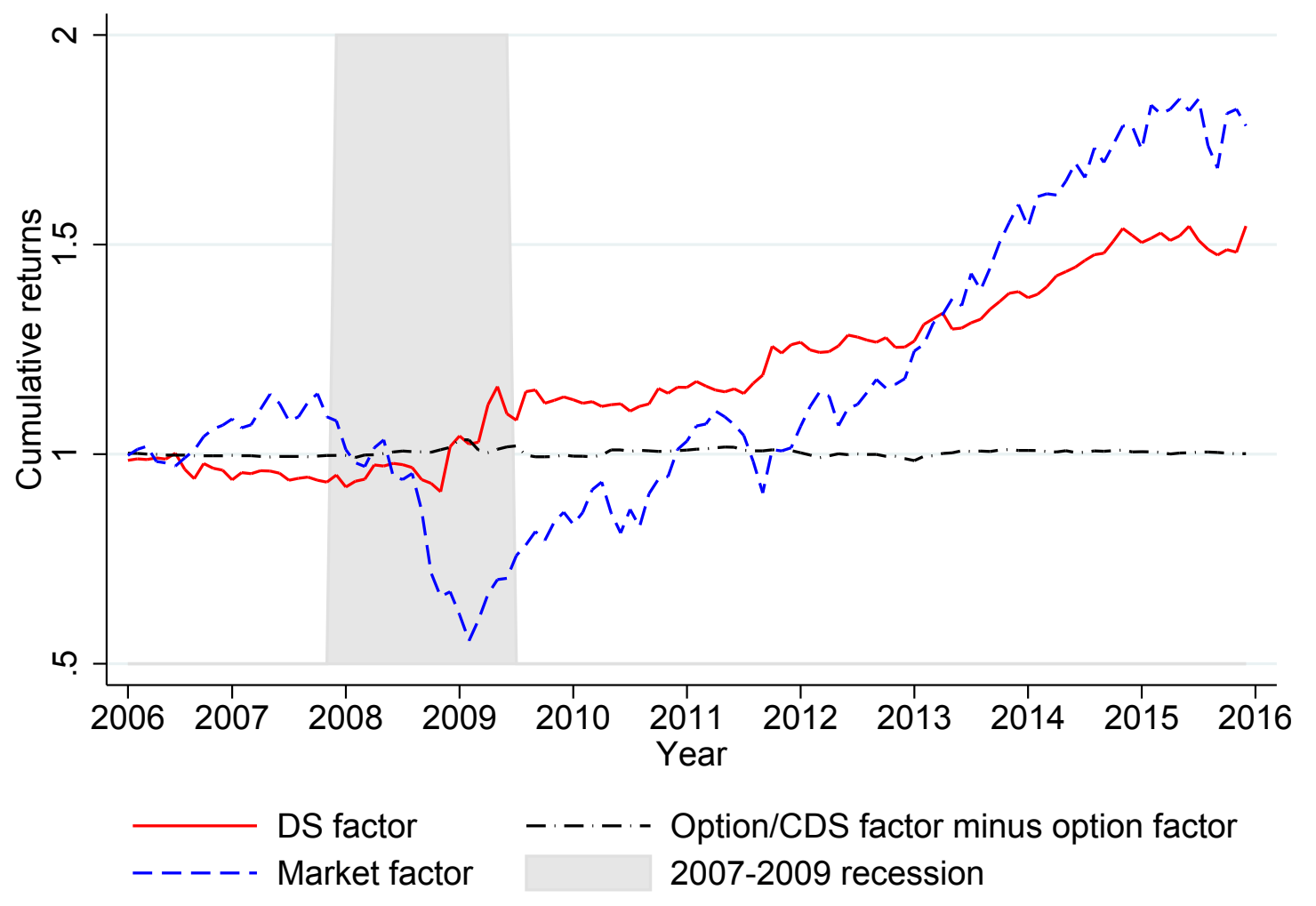




\section{Figure 6: Contribution of jumps to the volatility of medium-sized returns}

We compute the portion of intermediate-return variance that is explained by jumps for the 275 stocks in our sample. The charts show the average by month- $t$ DS decile, together with a fractional polynomial fit and $90 \%$ confidence intervals. Variance $\left(\sigma^{2}\right)$ is the rolling sum of squared 15-minute returns between 9:30-16:00 daily in months $t+1$ to $t+3$. The non-jump component of variance $\left(\sigma_{n j}^{2}\right)$ is computed with the MedRV estimator of Andersen, Dobrev, and Schaumburg (2012), and the portion of variance due to jumps is $\phi=\frac{\sigma^{2}-\sigma_{n j}^{2}}{\sigma^{2}}$. The variance measures are based on intermediate returns, that is returns between the $10^{t h}-40^{t h}$ and $60^{t h}-90^{t h}$ percentiles of the daily distribution of returns. The full sample includes 2006 to 2015 .

Full sample, post-formation

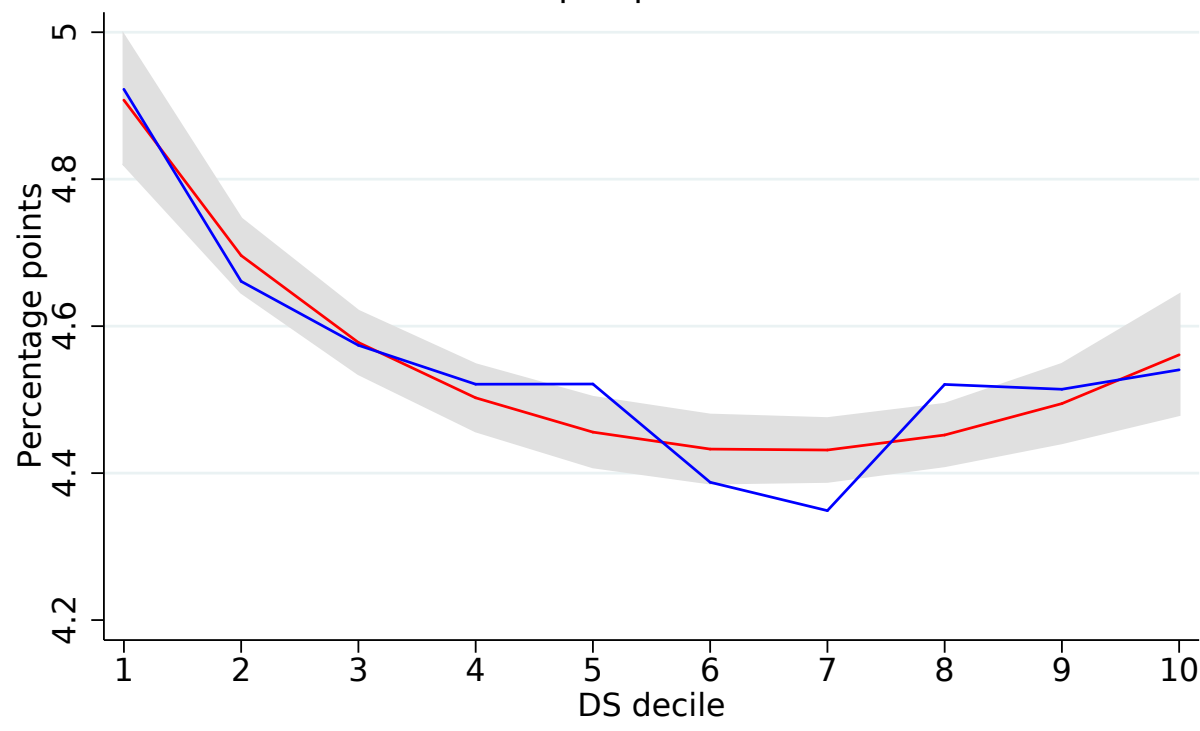

Average contribution $\quad 90 \% \mathrm{Cl}$

2008-2011, post-formation

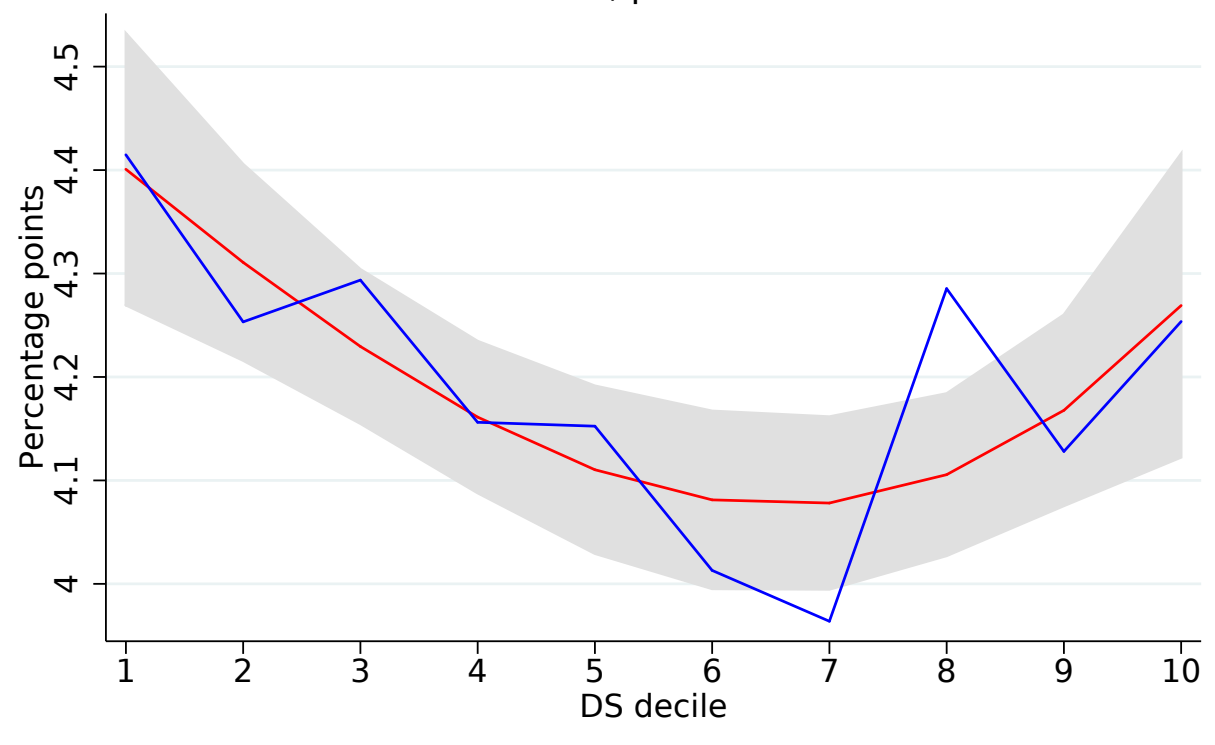

Average contribution

$90 \% \mathrm{Cl}$ 
Figure 7: Increase in the probability of intermediate returns under the options/CDS distribution, by DS decile

The figure shows the average (top chart) and $90^{\text {th }}$ percentile (bottom chart) increase in the probability of intermediate returns from the options-only distribution to the options/CDS distribution. See footnote 11 for the definition of intermediate returns and for the calculation of the increase in probability. The DS deciles and the probability increases are as of month $t$. The sample includes 2006 to 2015 .
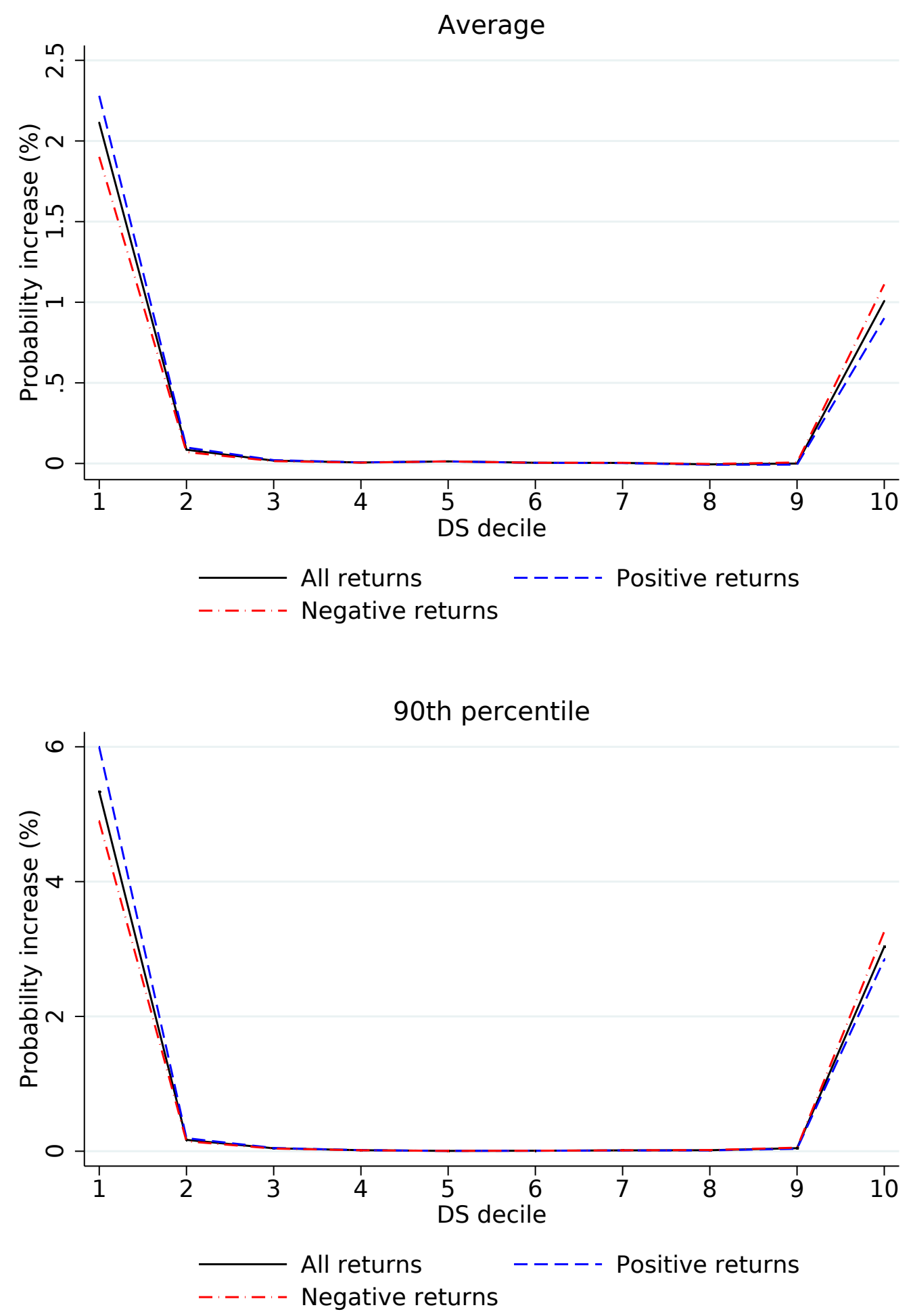
Figure 8: Skewed- $t$ distribution for different levels of skewness

The figure illustrates the shape of the skewed Student- $t$ distribution for different levels of skewness. Each distribution has a volatility of $15 \%, 5$ degrees of freedom, and the shape parameter is equal to -0.5 (negative skewness, blue dash-dot line), 0 (zero skewness, black solid line), and 0.5 (positive skewness, red dashed line).

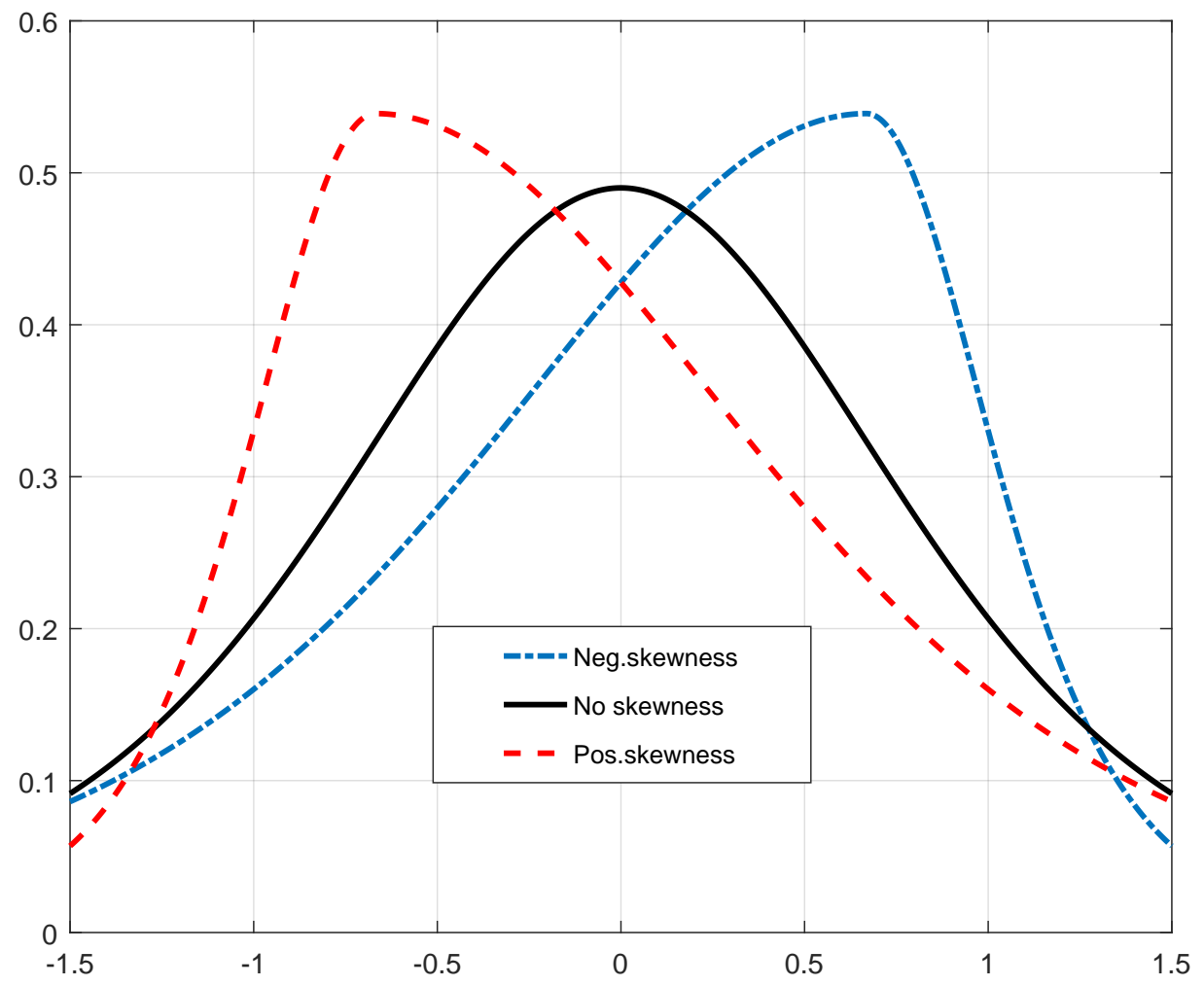


Figure 9: Realized volatility and standardized earnings surprises across DS deciles

The charts show the DS-decile average of two stock characteristics. DS deciles are recalculated each month $t$. The two stock characteristics are realized daily stock volatility one year prior to month $t$ (top), and average standardized earnings surprises (SUE) in the year up to month $t$ (Chan, Jegadeesh, and Lakonishok, 1996, p. 1685) (bottom). The sample includes 2006 to 2015.
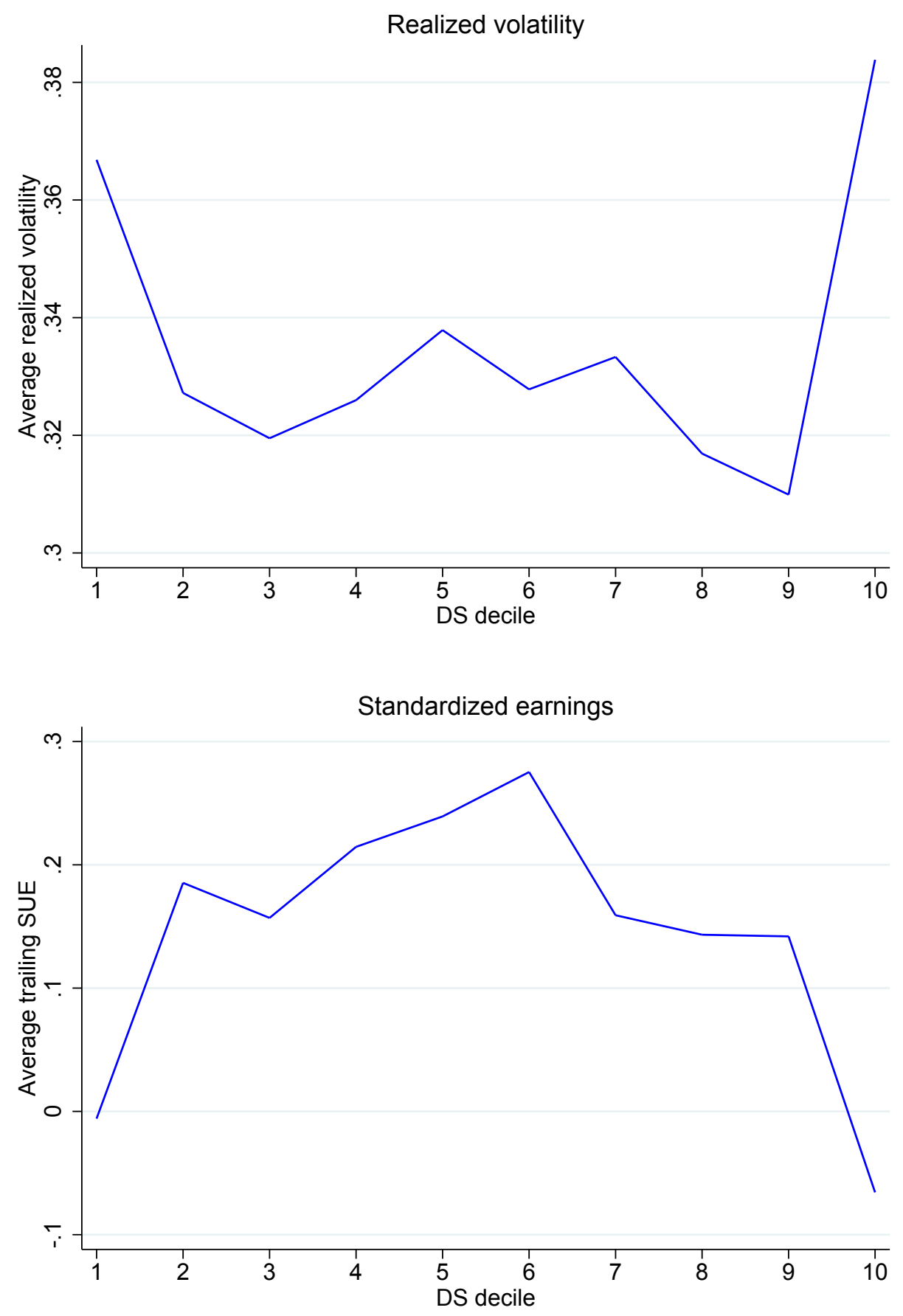


\section{Table 1: Selected balance-sheet characteristics}

The table presents descriptive summary statistics for the 275 companies for which we estimate the options/CDS risk-neutral return distributions. Book assets are reported in $\$$ million. Ratios are calculated with respect to book assets at the end of the previous year. The data is as of the end of fiscal year 2006 .

\begin{tabular}{l|cccc}
\hline & Average & $75^{t h}$ perc. & $50^{\text {th }}$ perc. & $25^{\text {th }}$ perc. \\
\hline Book assets & 62,899 & 31,777 & 12,864 & 6,590 \\
Sales ratio & 114.59 & 143.85 & 95.42 & 53.56 \\
Cash flow ratio & 16.45 & 21.81 & 15.97 & 9.91 \\
Investment ratio & 6.38 & 8.03 & 4.51 & 2.27 \\
R\&D ratio & 4.00 & 4.87 & 1.75 & 0.15 \\
Stock issuance ratio & -3.51 & 0.03 & -1.88 & -5.71 \\
Debt issuance ratio & 3.38 & 3.66 & 0.00 & -0.99 \\
\hline
\end{tabular}




\section{Table 2: Summary statistics on option-data availability}

The table reports the average and median number of daily option observations, and the associated volumes, after applying the filters discussed in Section 2. The statistics are reported separately for S\&P 500 index options and for options on the 275 companies for which we estimate options/CDS risk-neutral distributions. The statistics are shown by call and put option types ( $\mathrm{C}$ and $\mathrm{P}$, respectively), and for different moneyness levels. A call (put) option is out-of-the-money (OTM) if the strike price is above (below) the stock price. A put option is deep OTM if the strike price is less than $80 \%$ of the stock price. The sample includes 2006 to 2015.

\begin{tabular}{|c|c|c|c|c|c|}
\hline \multirow[b]{2}{*}{ Call/Put } & \multirow[b]{2}{*}{ Moneyness } & \multicolumn{4}{|c|}{ Options on the S\&P 500 index } \\
\hline & & Average obs. & Median obs. & Av. volume & Med. volume \\
\hline $\mathrm{C}$ & ITM & 5.40 & 4 & 6,541 & 788 \\
\hline $\mathrm{C}$ & OTM & 12.02 & 11 & 10,772 & 5,825 \\
\hline $\mathrm{P}$ & ITM & 4.29 & 3 & 5,023 & 709 \\
\hline $\mathrm{P}$ & OTM & 14.69 & 13 & 19,702 & 11,942 \\
\hline $\mathrm{P}$ & Deep OTM & 8.11 & 6 & 4,074 & 1,312 \\
\hline & & \multicolumn{4}{|c|}{ Options on the firms we study } \\
\hline Call/Put & Moneyness & Average obs. & Median obs. & Av. volume & Med. volume \\
\hline $\mathrm{C}$ & ITM & 2.91 & 2 & 393 & 66 \\
\hline $\mathrm{C}$ & OTM & 3.24 & 3 & 701 & 173 \\
\hline $\mathrm{P}$ & ITM & 2.21 & 2 & 256 & 48 \\
\hline $\mathrm{P}$ & OTM & 2.51 & 2 & 427 & 92 \\
\hline $\mathrm{P}$ & Deep OTM & 1.82 & 1 & 219 & 30 \\
\hline
\end{tabular}




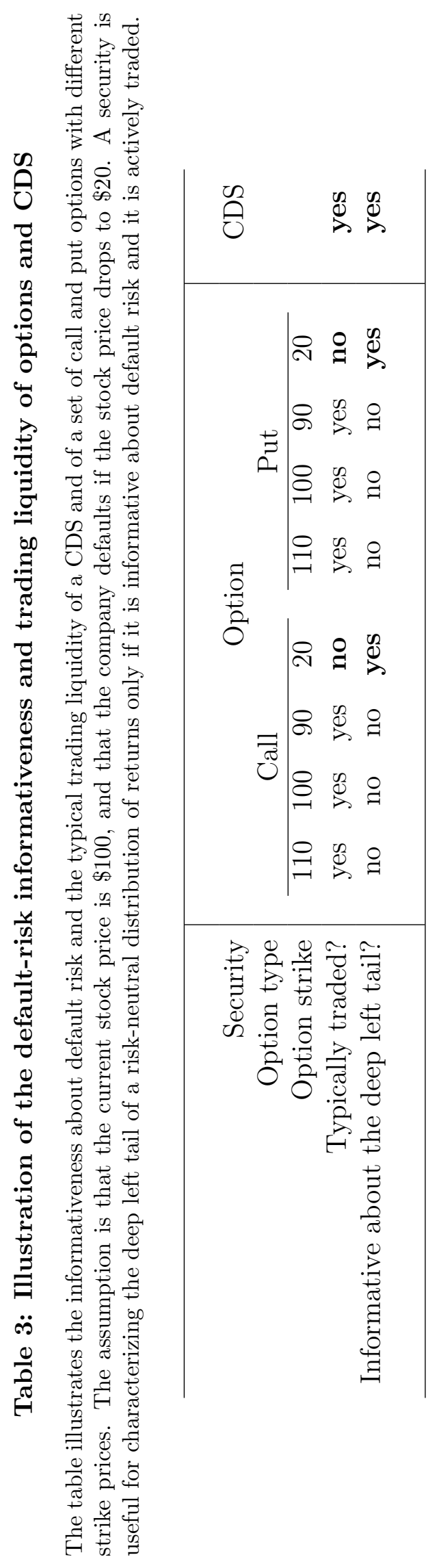




\section{Table 4: Default thresholds}

The table shows the default thresholds we use when extracting the options/CDS risk-neutral distributions. The thresholds are estimated on a sample of 167 firms with market capitalization in excess of 100 million that filed for Chapter 7 or Chapter 11 between 1990 and 2015, and that delisted within 30 days of bankruptcy. The thresholds are average cumulative returns over the three-month period leading to bankruptcy. In Panel A, they are calculated after double sorting firms based on size and leverage. Low/high leverage means leverage below/above the sample median. Large firms are those with market capitalization in excess of $\$ 1$ billion. Panel B shows the average of the four thresholds in Panel A (the average is taken over log returns), and $120 \%$ and $80 \%$ of the average. We use these thresholds in robustness tests.

\begin{tabular}{lcc}
\hline Panel A - Characteristics-based thresholds \\
& \multicolumn{2}{c}{ Log returns } \\
& Low leverage & High leverage \\
Market cap $<1$ bn & -1.68 & -1.21 \\
Market cap $\geq 1$ bn & -2.29 & -2.24 \\
& \multicolumn{2}{c}{ Arithmetic returns } \\
& Low leverage & High leverage \\
Market cap $<1$ bn & -0.81 & -0.70 \\
Market cap $\geq 1$ bn & -0.90 & -0.89 \\
& \multicolumn{2}{c}{} \\
\hline Panel B - Fixed thresholds & Arithmetic returns \\
& & -0.84 \\
Average of Panel A & -1.85 & -0.89 \\
$120 \%$ of average & -2.23 & -0.77 \\
$80 \%$ of average & -1.48 & \\
& &
\end{tabular}




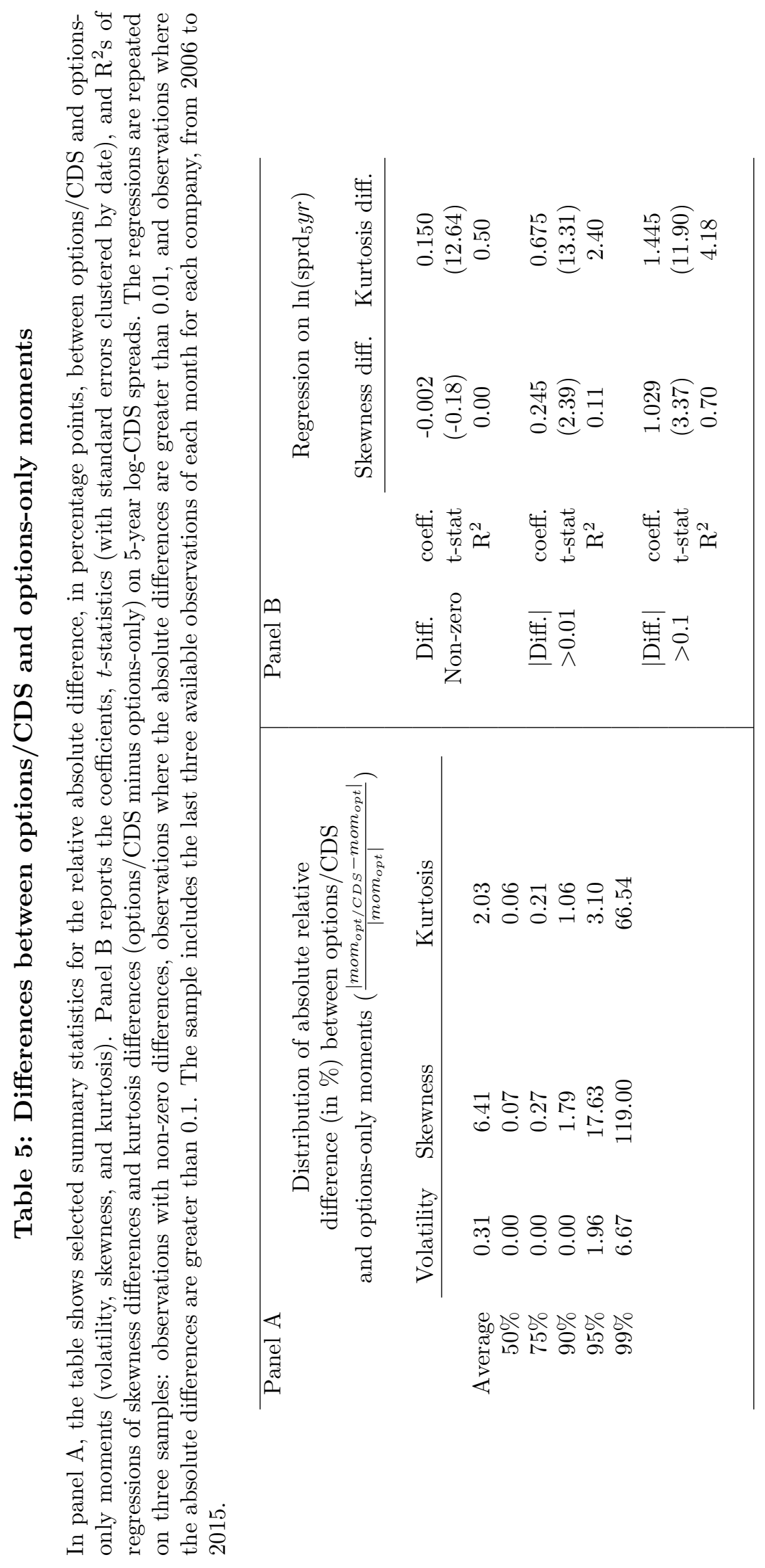




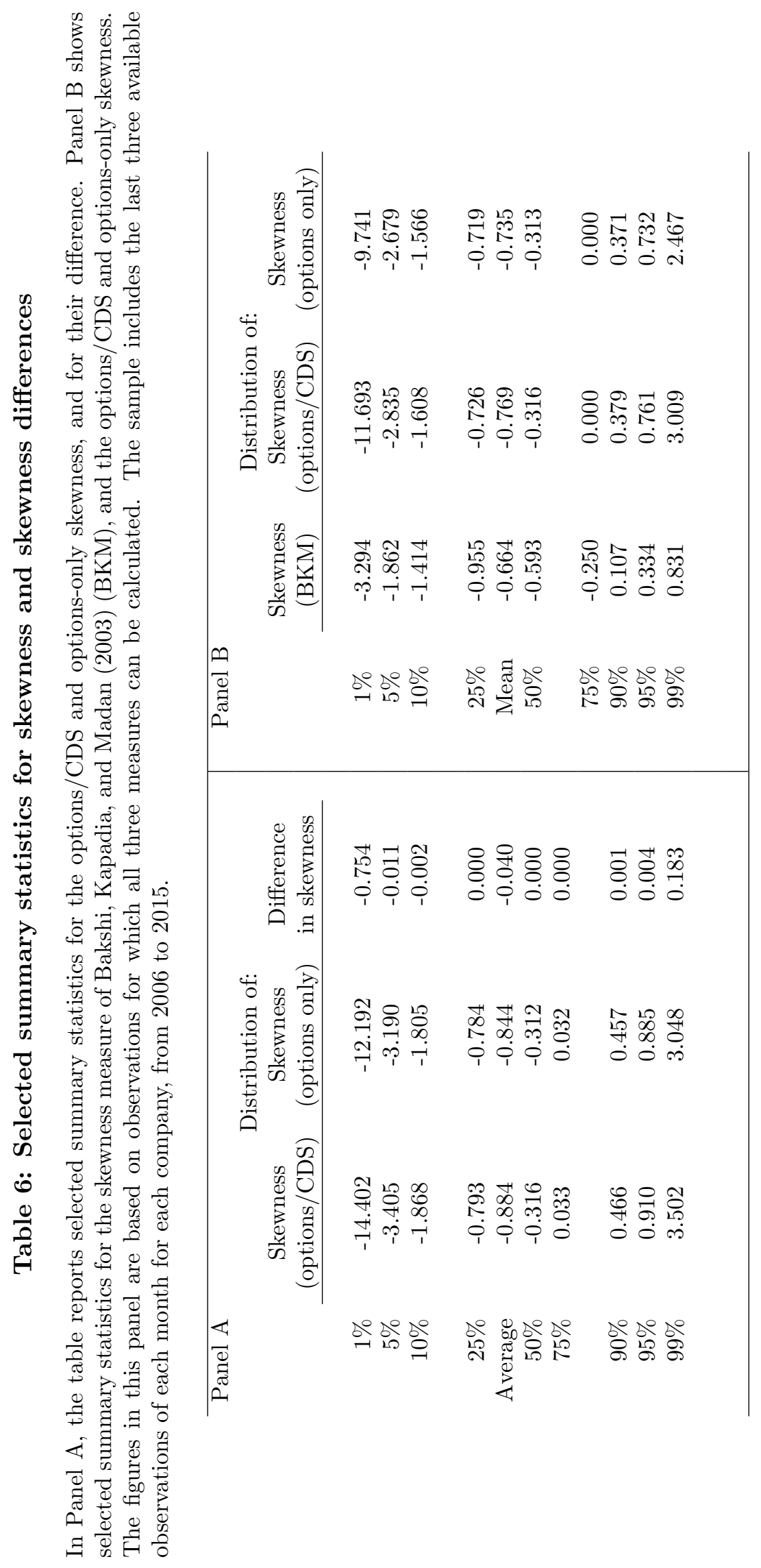




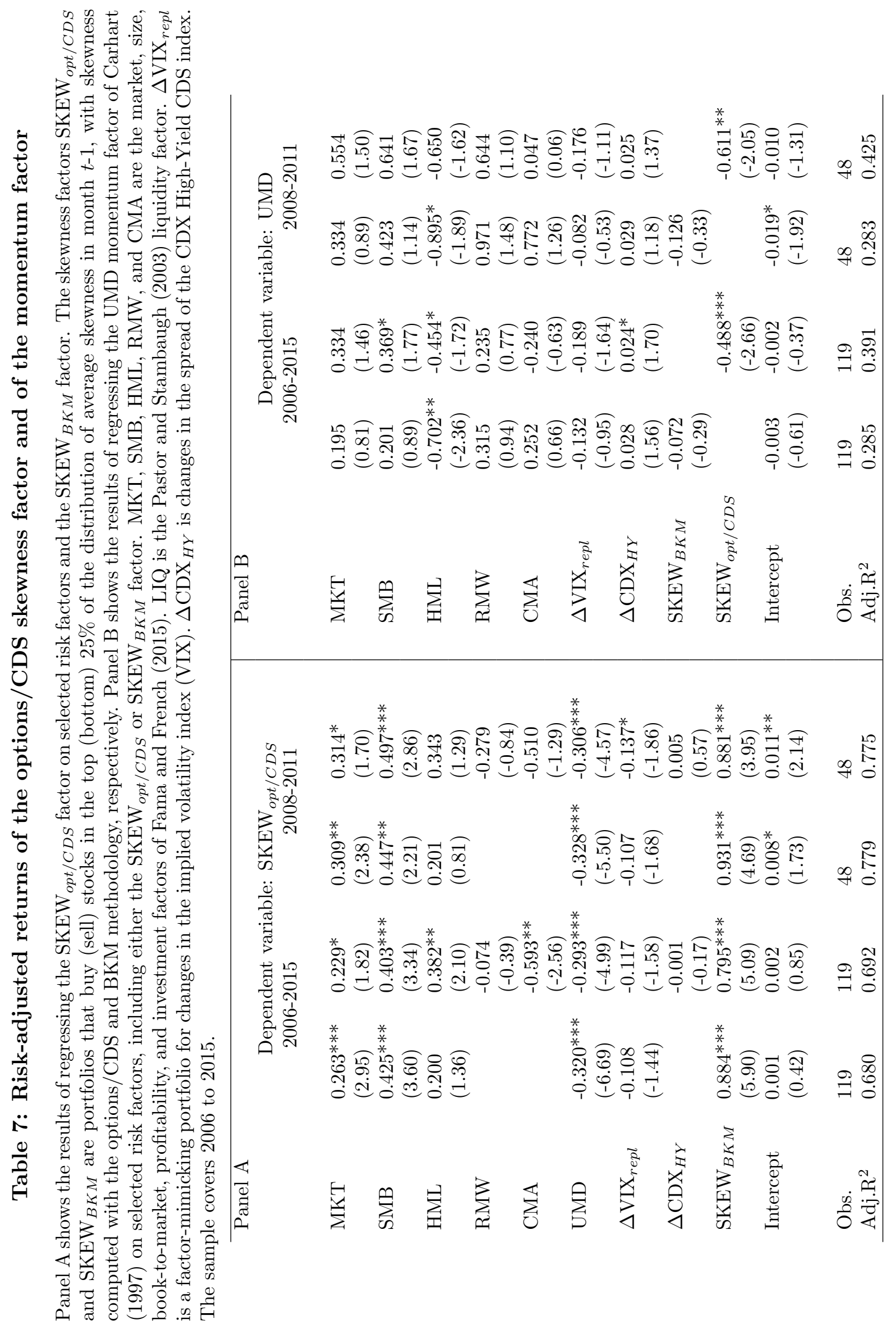




\section{Table 8: Time series intercept of the DS factor: full sample}

The table reports coefficients, intercepts, $t$-statistics, number of observations, and adjusted $\mathrm{R}^{2} \mathrm{~s}$ from regressions of the DS factor on the listed factors: $D S_{t}=\alpha+\sum_{i=1}^{N} \beta_{i} f_{t}^{i}+\varepsilon_{t}$. MKT, SMB, HML, RMW, and CMA are the market, size, book-to-market, profitability, and investment factors of Fama and French (2015). UMD is the Carhart (1997) momentum factor. LT REV and ST REV are the long run and short run reversals factors (see, among others, Fama and French, 1996 and Novy-Marx, 2012, and references therein). LIQ is the Pastor and Stambaugh (2003) liquidity factor. $\Delta \mathrm{VIX}_{r e p l}, \Delta \mathrm{VIX}_{\text {repl }}^{2}$, and $\mathrm{VRP}_{r e p l}$ are replicating portfolios for changes and squared changes in the implied volatility index VIX, and for the variance risk premium of Bollerslev, Tauchen, and Zhou (2009). $\mathrm{CDXX}_{H Y}$ is changes in the spread of the CDX high-yield CDS index. The $t$-statistics are based on heteroskedasticity-consistent standard errors. ${ }^{* * *}, * *$, and ${ }^{*}$ indicate statistical significance at the 1, 5, and $10 \%$ levels, respectively. The sample includes February 2006 to December 2015.

\begin{tabular}{|c|c|c|c|c|c|c|c|}
\hline & (1) & $(2)$ & (3) & (4) & (5) & $\begin{array}{c}(6) \\
\text { long leg }\end{array}$ & $\begin{array}{c}(7) \\
\text { short leg }\end{array}$ \\
\hline MKT & $\begin{array}{l}0.060 \\
(1.23)\end{array}$ & $\begin{array}{l}0.081 \\
(1.62)\end{array}$ & $\begin{array}{l}0.078 \\
(1.09)\end{array}$ & $\begin{array}{l}0.021 \\
(0.35)\end{array}$ & $\begin{array}{l}0.071 \\
(0.99)\end{array}$ & $\begin{array}{c}0.943^{* * *} \\
(11.48)\end{array}$ & $\begin{array}{c}0.921^{* * *} \\
(12.12)\end{array}$ \\
\hline SMB & $\begin{array}{l}-0.016 \\
(-0.22)\end{array}$ & $\begin{array}{l}0.015 \\
(0.21)\end{array}$ & $\begin{array}{l}-0.004 \\
(-0.05)\end{array}$ & $\begin{array}{l}-0.056 \\
(-0.78)\end{array}$ & $\begin{array}{l}0.000 \\
(0.00)\end{array}$ & $\begin{array}{l}-0.022 \\
(-0.22)\end{array}$ & $\begin{array}{c}0.034 \\
(0.34)\end{array}$ \\
\hline HML & $\begin{array}{l}0.001 \\
(0.01)\end{array}$ & $\begin{array}{l}0.191 \\
(1.44)\end{array}$ & $\begin{array}{l}0.202 \\
(1.49)\end{array}$ & $\begin{array}{l}0.145 \\
(1.16)\end{array}$ & $\begin{array}{l}0.209 \\
(1.53)\end{array}$ & $\begin{array}{l}0.114 \\
(0.86)\end{array}$ & $\begin{array}{l}-0.031 \\
(-0.24)\end{array}$ \\
\hline UMD & $\begin{array}{c}-0.164^{* * *} \\
(-3.42)\end{array}$ & $\begin{array}{c}-0.146^{* * *} \\
(-3.72)\end{array}$ & $\begin{array}{c}-0.132^{* * *} \\
(-2.64)\end{array}$ & $\begin{array}{c}-0.098^{* *} \\
(-2.10)\end{array}$ & $\begin{array}{c}-0.138^{* * *} \\
(-2.78)\end{array}$ & $\begin{array}{l}-0.075 \\
(-1.37)\end{array}$ & $\begin{array}{l}0.023 \\
(0.43)\end{array}$ \\
\hline LIQ & $\begin{array}{l}0.045 \\
(0.82)\end{array}$ & $\begin{array}{l}0.031 \\
(0.52)\end{array}$ & $\begin{array}{c}0.039 \\
(0.62)\end{array}$ & $\begin{array}{l}0.030 \\
(0.50)\end{array}$ & $\begin{array}{l}0.040 \\
(0.63)\end{array}$ & $\begin{array}{l}-0.000 \\
(-0.00)\end{array}$ & $\begin{array}{l}-0.030 \\
(-0.40)\end{array}$ \\
\hline RMW & & $\begin{array}{l}-0.110 \\
(-0.79)\end{array}$ & $\begin{array}{l}-0.147 \\
(-1.14)\end{array}$ & $\begin{array}{l}-0.089 \\
(-0.73)\end{array}$ & $\begin{array}{l}-0.134 \\
(-0.97)\end{array}$ & $\begin{array}{l}0.167 \\
(1.16)\end{array}$ & $\begin{array}{l}0.257 \\
(1.59)\end{array}$ \\
\hline CMA & & $\begin{array}{l}-0.177 \\
(-1.02)\end{array}$ & $\begin{array}{l}-0.141 \\
(-0.84)\end{array}$ & $\begin{array}{l}-0.059 \\
(-0.35)\end{array}$ & $\begin{array}{l}-0.145 \\
(-0.86)\end{array}$ & $\begin{array}{l}0.027 \\
(0.13)\end{array}$ & $\begin{array}{l}0.085 \\
(0.40)\end{array}$ \\
\hline LT REV & & $\begin{array}{c}-0.199^{* *} \\
(-1.99)\end{array}$ & $\begin{array}{c}-0.241 * * * \\
(-2.63)\end{array}$ & $\begin{array}{c}-0.184^{*} \\
(-1.83)\end{array}$ & $\begin{array}{c}-0.215^{* *} \\
(-2.03)\end{array}$ & $\begin{array}{l}-0.089 \\
(-0.62)\end{array}$ & $\begin{array}{l}0.095 \\
(0.76)\end{array}$ \\
\hline ST REV & & $\begin{array}{c}-0.126^{*} \\
(-1.68)\end{array}$ & $\begin{array}{c}-0.135^{*} \\
(-1.82)\end{array}$ & $\begin{array}{c}-0.118^{*} \\
(-1.69)\end{array}$ & $\begin{array}{c}-0.132^{*} \\
(-1.78)\end{array}$ & $\begin{array}{l}0.029 \\
(0.37)\end{array}$ & $\begin{array}{c}0.147^{*} \\
(1.78)\end{array}$ \\
\hline$\Delta \mathrm{VIX}_{r e p l}$ & $\begin{array}{c}-0.235^{* * *} \\
(-4.15)\end{array}$ & $\begin{array}{c}-0.248^{* * *} \\
(-3.96)\end{array}$ & $\begin{array}{c}-0.212^{* * *} \\
(-3.64)\end{array}$ & $\begin{array}{c}-0.219^{* * *} \\
(-4.22)\end{array}$ & $\begin{array}{c}-0.216^{* * *} \\
(-3.76)\end{array}$ & $\begin{array}{c}-0.195^{*} \\
(-1.97)\end{array}$ & $\begin{array}{l}0.025 \\
(0.32)\end{array}$ \\
\hline$\Delta \mathrm{VIX}_{r e p l}^{2}$ & & & $\begin{array}{l}0.132 \\
(0.99)\end{array}$ & $\begin{array}{l}0.006 \\
(0.06)\end{array}$ & $\begin{array}{l}0.112 \\
(0.91)\end{array}$ & $\begin{array}{c}0.330^{* *} \\
(2.27)\end{array}$ & $\begin{array}{c}0.323^{* * *} \\
(2.67)\end{array}$ \\
\hline $\mathrm{VRP}_{r e p l}$ & & & $\begin{array}{l}-0.061 \\
(-0.50)\end{array}$ & $\begin{array}{l}-0.119 \\
(-1.43)\end{array}$ & $\begin{array}{l}-0.089 \\
(-0.63)\end{array}$ & $\begin{array}{l}-0.062 \\
(-0.43)\end{array}$ & $\begin{array}{c}0.058 \\
(0.40)\end{array}$ \\
\hline$\Delta \mathrm{CDX}_{H Y}$ & & & $\begin{array}{l}0.001 \\
(0.14)\end{array}$ & $\begin{array}{l}-0.000 \\
(-0.11)\end{array}$ & $\begin{array}{l}0.000 \\
(0.08)\end{array}$ & $\begin{array}{c}0.005 \\
(1.11)\end{array}$ & $\begin{array}{l}0.006 \\
(1.32)\end{array}$ \\
\hline $\mathrm{SKEW}_{o p t / C D S}$ & & & & $\begin{array}{c}0.197^{* * *} \\
(3.00)\end{array}$ & & $\begin{array}{c}0.372^{* * *} \\
(5.63)\end{array}$ & $\begin{array}{c}0.175^{* *} \\
(2.43)\end{array}$ \\
\hline $\mathrm{SKEW}_{B K M}$ & & & & & $\begin{array}{l}0.070 \\
(0.59)\end{array}$ & & \\
\hline Intercept & $\begin{array}{c}0.003^{*} \\
(1.86)\end{array}$ & $\begin{array}{c}0.004^{* *} \\
(2.07)\end{array}$ & $\begin{array}{c}0.004^{* *} \\
(2.17)\end{array}$ & $\begin{array}{c}0.003^{* *} \\
(1.98)\end{array}$ & $\begin{array}{c}0.004^{* *} \\
(2.17)\end{array}$ & $\begin{array}{l}0.003 \\
(1.46)\end{array}$ & $\begin{array}{l}-0.000 \\
(-0.07)\end{array}$ \\
\hline Obs. & 119 & 119 & 119 & 119 & 119 & 119 & 119 \\
\hline Adj. $R^{2}$ & 0.329 & 0.397 & 0.389 & 0.440 & 0.385 & 0.904 & 0.865 \\
\hline
\end{tabular}




\section{Table 9: Time series intercept of the DS factor: between 2008 and 2011}

The table reports coefficients, intercepts, $t$-statistics, number of observations, and adjusted $\mathrm{R}^{2} \mathrm{~s}$ from regressions of the DS factor on the listed factors: $D S_{t}=\alpha+\sum_{i=1}^{N} \beta_{i} f_{t}^{i}+\varepsilon_{t}$. MKT, SMB, HML, RMW, and CMA are the market, size, book-to-market, profitability, and investment factors of Fama and French (2015). UMD is the Carhart (1997) momentum factor. LT REV and ST REV are the long run and short run reversals factors (see, among others, Fama and French, 1996 and Novy-Marx, 2012, and references therein). LIQ is the Pastor and Stambaugh (2003) liquidity factor. $\Delta \mathrm{VIX}_{r e p l}, \Delta \mathrm{VIX}_{\text {repl }}^{2}$, and $\mathrm{VRP}_{\text {repl }}$ are replicating portfolios for changes and squared changes in the implied volatility index VIX, and for the variance risk premium of Bollerslev, Tauchen, and Zhou (2009). $\mathrm{CDXX}_{H Y}$ is changes in the spread of the CDX high-yield CDS index. The $t$-statistics are based on heteroskedasticity-consistent standard errors. ${ }^{* * *},{ }^{* *}$, and ${ }^{*}$ indicate statistical significance at the 1, 5, and $10 \%$ levels, respectively.

\begin{tabular}{|c|c|c|c|c|c|c|c|}
\hline & (1) & (2) & (3) & (4) & (5) & $\begin{array}{c}(6) \\
\text { long leg }\end{array}$ & $\begin{array}{c}(7) \\
\text { short leg }\end{array}$ \\
\hline $\mathrm{MKT}$ & $\begin{array}{l}0.070 \\
(0.88)\end{array}$ & $\begin{array}{l}0.056 \\
(0.69)\end{array}$ & $\begin{array}{l}0.132 \\
(1.18)\end{array}$ & $\begin{array}{l}0.025 \\
(0.24)\end{array}$ & $\begin{array}{l}0.118 \\
(1.19)\end{array}$ & $\begin{array}{c}0.959^{* * *} \\
(6.48)\end{array}$ & $\begin{array}{c}0.933^{* * *} \\
(6.22)\end{array}$ \\
\hline SMB & $\begin{array}{l}-0.082 \\
(-0.54)\end{array}$ & $\begin{array}{l}-0.043 \\
(-0.29)\end{array}$ & $\begin{array}{l}0.011 \\
(0.08)\end{array}$ & $\begin{array}{l}-0.110 \\
(-0.78)\end{array}$ & $\begin{array}{l}-0.023 \\
(-0.18)\end{array}$ & $\begin{array}{c}0.066 \\
(0.36)\end{array}$ & $\begin{array}{c}0.176 \\
(1.03)\end{array}$ \\
\hline HML & $\begin{array}{l}0.008 \\
(0.03)\end{array}$ & $\begin{array}{l}0.243 \\
(1.03)\end{array}$ & $\begin{array}{l}0.338 \\
(1.47)\end{array}$ & $\begin{array}{l}0.281 \\
(1.52)\end{array}$ & $\begin{array}{c}0.463^{*} \\
(1.95)\end{array}$ & $\begin{array}{l}0.045 \\
(0.19)\end{array}$ & $\begin{array}{l}-0.236 \\
(-0.97)\end{array}$ \\
\hline UMD & $\begin{array}{c}-0.210^{* * *} \\
(-4.25)\end{array}$ & $\begin{array}{c}-0.140^{* *} \\
(-2.60)\end{array}$ & $\begin{array}{c}-0.129^{*} \\
(-2.00)\end{array}$ & $\begin{array}{l}-0.075 \\
(-1.19)\end{array}$ & $\begin{array}{c}-0.170^{* *} \\
(-2.48)\end{array}$ & $\begin{array}{l}-0.101 \\
(-1.18)\end{array}$ & $\begin{array}{l}-0.026 \\
(-0.35)\end{array}$ \\
\hline LIQ & $\begin{array}{l}0.049 \\
(0.57)\end{array}$ & $\begin{array}{l}0.055 \\
(0.57)\end{array}$ & $\begin{array}{l}0.097 \\
(1.11)\end{array}$ & $\begin{array}{l}0.075 \\
(0.91)\end{array}$ & $\begin{array}{l}0.136 \\
(1.58)\end{array}$ & $\begin{array}{l}-0.067 \\
(-0.56)\end{array}$ & $\begin{array}{l}-0.142 \\
-1.25)\end{array}$ \\
\hline RMW & & $\begin{array}{l}-0.334 \\
(-1.19)\end{array}$ & $\begin{array}{c}-0.440^{*} \\
-1.86)\end{array}$ & $\begin{array}{l}-0.311 \\
(-1.24)\end{array}$ & $\begin{array}{l}-0.419^{*} \\
(-1.79)\end{array}$ & $\begin{array}{c}0.555^{*} \\
(1.89)\end{array}$ & $\begin{array}{c}0.867^{* * *} \\
(3.63)\end{array}$ \\
\hline CMA & & $\begin{array}{c}-0.508^{* *} \\
(-2.05)\end{array}$ & $\begin{array}{c}-0.565^{*} \\
-1.96)\end{array}$ & $\begin{array}{l}-0.433 \\
(-1.51)\end{array}$ & $\begin{array}{c}-0.694^{* *} \\
(-2.70)\end{array}$ & $\begin{array}{l}-0.072 \\
(-0.19)\end{array}$ & $\begin{array}{c}0.362 \\
(1.18)\end{array}$ \\
\hline LT REV & & $\begin{array}{l}-0.074 \\
(-0.47)\end{array}$ & $\begin{array}{l}-0.183 \\
(-1.35)\end{array}$ & $\begin{array}{l}-0.102 \\
(-0.61)\end{array}$ & $\begin{array}{l}0.022 \\
(0.14)\end{array}$ & $\begin{array}{l}-0.036 \\
(-0.18)\end{array}$ & $\begin{array}{l}0.066 \\
(0.45)\end{array}$ \\
\hline ST REV & & $\begin{array}{l}-0.169 \\
(-1.55)\end{array}$ & $\begin{array}{c}-0.210^{*} \\
(-1.87)\end{array}$ & $\begin{array}{l}-0.177 \\
(-1.56)\end{array}$ & $\begin{array}{c}-0.218^{* *} \\
(-2.05)\end{array}$ & $\begin{array}{l}0.171 \\
(1.32)\end{array}$ & $\begin{array}{c}0.348^{* * *} \\
(3.60)\end{array}$ \\
\hline$\Delta \mathrm{VIX}_{r e p l}$ & $\begin{array}{c}-0.235^{* * *} \\
(-3.78)\end{array}$ & $\begin{array}{c}-0.263^{* * *} \\
(-4.33)\end{array}$ & $\begin{array}{c}-0.201^{* * *} \\
(-3.31)\end{array}$ & $\begin{array}{c}-0.215^{* * *} \\
(-3.73)\end{array}$ & $\begin{array}{c}-0.249 * * * \\
(-3.70)\end{array}$ & $\begin{array}{l}-0.146 \\
(-1.45)\end{array}$ & $\begin{array}{c}0.069 \\
(0.79)\end{array}$ \\
\hline$\Delta \mathrm{VIX}_{r e p l}^{2}$ & & & $\begin{array}{c}0.315^{* *} \\
(2.31)\end{array}$ & $\begin{array}{l}0.109 \\
(0.70)\end{array}$ & $\begin{array}{c}0.161 \\
(1.09)\end{array}$ & $\begin{array}{l}0.370^{*} \\
(1.90)\end{array}$ & $\begin{array}{c}0.262^{*} \\
(1.73)\end{array}$ \\
\hline $\mathrm{VRP}_{r e p l}$ & & & $\begin{array}{l}-0.191 \\
(-1.49)\end{array}$ & $\begin{array}{c}-0.204^{* *} \\
(-2.06)\end{array}$ & $\begin{array}{c}-0.406^{* * *} \\
(-3.01)\end{array}$ & $\begin{array}{l}0.070 \\
(0.47)\end{array}$ & $\begin{array}{l}0.274^{*} \\
(1.94)\end{array}$ \\
\hline$\Delta \mathrm{CDX}_{H Y}$ & & & $\begin{array}{l}0.008 \\
(1.24)\end{array}$ & $\begin{array}{l}0.004 \\
(0.85)\end{array}$ & $\begin{array}{l}0.007 \\
(1.14)\end{array}$ & $\begin{array}{l}0.011^{*} \\
(1.76)\end{array}$ & $\begin{array}{l}0.007 \\
(1.13)\end{array}$ \\
\hline $\mathrm{SKEW}_{\text {opt } / C D S}$ & & & & $\begin{array}{c}0.256^{* * *} \\
(3.03)\end{array}$ & & $\begin{array}{c}0.423^{* * *} \\
(3.87)\end{array}$ & $\begin{array}{l}0.166 \\
(1.53)\end{array}$ \\
\hline SKEW $_{B K M}$ & & & & & $\begin{array}{c}0.427^{* *} \\
(2.35)\end{array}$ & & \\
\hline Intercept & $\begin{array}{l}0.004 \\
(1.33)\end{array}$ & $\begin{array}{c}0.008^{* *} \\
(2.05)\end{array}$ & $\begin{array}{c}0.008^{* *} \\
(2.05)\end{array}$ & $\begin{array}{l}0.006^{*} \\
(1.95)\end{array}$ & $\begin{array}{c}0.011^{* * *} * \\
(3.06)\end{array}$ & $\begin{array}{l}-0.001 \\
(-0.27)\end{array}$ & $\begin{array}{c}-0.008^{*} \\
(-1.98)\end{array}$ \\
\hline Obs. & 48 & 48 & 48 & 48 & 48 & 48 & 48 \\
\hline $\operatorname{Adj} . R^{2}$ & 0.455 & 0.513 & 0.546 & 0.623 & 0.590 & 0.929 & 0.908 \\
\hline
\end{tabular}


Table 10: Fama-MacBeth regressions (1/2)

The table shows the second-stage coefficients from Fama and MacBeth (1973) regressions. The test assets are 25 book-to-market/size portfolios replicated using the stocks with available volatility spreads (Bali and Hovakimian, 2009) and smirks (Xing, Zhang, and Zhao, 2010), and 10 decile portfolios based on the DS measure in month $t$ - 1 . The characteristics (portfolios averages in month $t-1$ ), are idiosyncratic volatility (Ang, Hodrick, Xing, and Zhang, 2006) (ivol), average 5-year CDS log-spread $\left(\operatorname{sprd}_{5 y r}\right)$, hybrid tail covariance (Bali, Cakici, and Whitelaw, 2014) ( $\left.\operatorname{cov}_{\text {tail }}\right)$, changes in call/put implied volatility of An, Ang, Bali, and Cakici (2014) ( $\Delta$ cvol and $\Delta$ pvol), and volatility spreads (vspread) and smirks (smirk). Adj. $R_{c r}^{2}$ is the average adj. $\mathrm{R}^{2}$ of the second-stage regressions. The sample covers February 2006 to December 2015.

\begin{tabular}{|c|c|c|c|c|c|c|c|c|}
\hline & \multicolumn{4}{|c|}{$2006-2015$} & \multicolumn{4}{|c|}{$2008-2011$} \\
\hline & $(1)$ & $(2)$ & (3) & (4) & $(5)$ & (6) & $(7)$ & $(8)$ \\
\hline$\lambda^{0}$ & $\begin{array}{l}0.034 \\
(1.37)\end{array}$ & $\begin{array}{l}0.023 \\
(0.94)\end{array}$ & $\begin{array}{l}0.027 \\
(1.61)\end{array}$ & $\begin{array}{l}0.019 \\
(1.16)\end{array}$ & $\begin{array}{l}0.003 \\
(0.07)\end{array}$ & $\begin{array}{l}0.004 \\
(0.10)\end{array}$ & $\begin{array}{l}0.023 \\
(0.87)\end{array}$ & $\begin{array}{l}0.020 \\
(0.63)\end{array}$ \\
\hline ivol & $\begin{array}{l}-0.251^{*} \\
(-1.83)\end{array}$ & $\begin{array}{l}-0.215^{*} \\
(-1.77)\end{array}$ & $\begin{array}{l}-0.154^{*} \\
(-1.71)\end{array}$ & $\begin{array}{l}-0.153^{*} \\
(-1.70)\end{array}$ & $\begin{array}{l}-0.293 \\
(-1.35)\end{array}$ & $\begin{array}{l}-0.168 \\
(-0.93)\end{array}$ & $\begin{array}{l}-0.285^{* *} \\
(-2.17)\end{array}$ & $\begin{array}{l}-0.234 \\
(-1.58)\end{array}$ \\
\hline $\operatorname{sprd}_{5 y r}$ & $\begin{array}{l}0.354 \\
(1.04)\end{array}$ & $\begin{array}{l}0.235 \\
(0.72)\end{array}$ & $\begin{array}{l}0.248 \\
(0.94)\end{array}$ & $\begin{array}{l}0.133 \\
(0.52)\end{array}$ & $\begin{array}{l}-0.015 \\
(-0.03)\end{array}$ & $\begin{array}{l}0.058 \\
(0.11)\end{array}$ & $\begin{array}{l}0.259 \\
(0.72)\end{array}$ & $\begin{array}{l}0.170 \\
(0.39)\end{array}$ \\
\hline $\operatorname{cov}_{\text {tail }}$ & $\begin{array}{l}-0.007 \\
(-0.96)\end{array}$ & $\begin{array}{l}-0.007 \\
(-0.97)\end{array}$ & $\begin{array}{l}-0.010 \\
(-1.55)\end{array}$ & $\begin{array}{l}-0.011^{*} \\
(-1.87)\end{array}$ & $\begin{array}{l}-0.012^{*} \\
(-1.93)\end{array}$ & $\begin{array}{l}-0.012^{*} \\
(-1.99)\end{array}$ & $\begin{array}{l}-0.010^{* *} \\
(-2.08)\end{array}$ & $\begin{array}{c}-0.008 \\
(-1.18)\end{array}$ \\
\hline$\Delta$ cvol & $\begin{array}{l}0.098 \\
(0.93)\end{array}$ & & $\begin{array}{l}0.100 \\
(1.13)\end{array}$ & $\begin{array}{l}0.121 \\
(1.31)\end{array}$ & $\begin{array}{l}0.215 \\
(1.51)\end{array}$ & & $\begin{array}{l}0.194^{*} \\
(1.85)\end{array}$ & $\begin{array}{l}0.214 \\
(1.51)\end{array}$ \\
\hline$\Delta$ pvol & $\begin{array}{l}-0.027 \\
(-0.27)\end{array}$ & & $\begin{array}{l}-0.049 \\
(-0.58)\end{array}$ & $\begin{array}{l}-0.066 \\
(-0.77)\end{array}$ & $\begin{array}{l}-0.223 \\
(-1.47)\end{array}$ & & $\begin{array}{l}-0.200^{*} \\
(-1.78)\end{array}$ & $\begin{array}{l}-0.206 \\
(-1.39)\end{array}$ \\
\hline vspread & $\begin{array}{l}0.034 \\
(0.80)\end{array}$ & $\begin{array}{l}0.028 \\
(0.69)\end{array}$ & & & $\begin{array}{l}0.008 \\
(0.10)\end{array}$ & $\begin{array}{l}0.007 \\
(0.09)\end{array}$ & & \\
\hline smirk & $\begin{array}{l}0.079 \\
(0.92)\end{array}$ & $\begin{array}{l}0.080 \\
(0.94)\end{array}$ & & & $\begin{array}{l}0.205^{*} \\
(1.94)\end{array}$ & $\begin{array}{l}0.139 \\
(1.40)\end{array}$ & & \\
\hline MKT & $\begin{array}{l}0.003 \\
(0.37)\end{array}$ & $\begin{array}{l}0.007 \\
(0.78)\end{array}$ & $\begin{array}{l}0.002 \\
(0.25)\end{array}$ & $\begin{array}{l}0.005 \\
(0.56)\end{array}$ & $\begin{array}{l}0.012 \\
(0.98)\end{array}$ & $\begin{array}{l}0.013 \\
(1.14)\end{array}$ & $\begin{array}{l}0.010 \\
(0.79)\end{array}$ & $\begin{array}{l}0.005 \\
(0.39)\end{array}$ \\
\hline SMB & $\begin{array}{l}0.002 \\
(0.46)\end{array}$ & $\begin{array}{l}0.002 \\
(0.64)\end{array}$ & $\begin{array}{l}0.002 \\
(0.46)\end{array}$ & $\begin{array}{l}0.002 \\
(0.59)\end{array}$ & $\begin{array}{l}0.002 \\
(0.43)\end{array}$ & $\begin{array}{l}-0.001 \\
(-0.20)\end{array}$ & $\begin{array}{l}0.001 \\
(0.33)\end{array}$ & $\begin{array}{l}-0.001 \\
(-0.33)\end{array}$ \\
\hline HML & $\begin{array}{l}-0.007 \\
(-1.36)\end{array}$ & $\begin{array}{l}-0.008 \\
(-1.62)\end{array}$ & $\begin{array}{l}-0.005 \\
(-1.11)\end{array}$ & $\begin{array}{l}-0.004 \\
(-0.88)\end{array}$ & $\begin{array}{l}0.006 \\
(0.77)\end{array}$ & $\begin{array}{l}0.004 \\
(0.53)\end{array}$ & $\begin{array}{l}0.003 \\
(0.44)\end{array}$ & $\begin{array}{l}0.005 \\
(0.64)\end{array}$ \\
\hline UMD & $\begin{array}{l}-0.002 \\
(-0.20)\end{array}$ & $\begin{array}{l}0.004 \\
(0.31)\end{array}$ & $\begin{array}{l}-0.004 \\
(-0.40)\end{array}$ & $\begin{array}{l}-0.006 \\
(-0.59)\end{array}$ & $\begin{array}{l}-0.006 \\
(-0.27)\end{array}$ & $\begin{array}{l}0.007 \\
(0.32)\end{array}$ & $\begin{array}{l}-0.002 \\
(-0.13)\end{array}$ & $\begin{array}{l}-0.001 \\
(-0.09)\end{array}$ \\
\hline LT REV & $\begin{array}{l}-0.006^{*} \\
(-1.71)\end{array}$ & $\begin{array}{l}-0.005 \\
(-1.32)\end{array}$ & $\begin{array}{l}-0.003 \\
(-1.03)\end{array}$ & $\begin{array}{l}-0.003 \\
(-0.77)\end{array}$ & $\begin{array}{l}-0.001 \\
(-0.18)\end{array}$ & $\begin{array}{l}0.002 \\
(0.26)\end{array}$ & $\begin{array}{l}0.001 \\
(0.21)\end{array}$ & $\begin{array}{l}0.001 \\
(0.10)\end{array}$ \\
\hline ST REV & $\begin{array}{l}-0.008 \\
(-1.26)\end{array}$ & $\begin{array}{l}-0.009 \\
(-1.21)\end{array}$ & $\begin{array}{l}-0.008 \\
(-1.11)\end{array}$ & $\begin{array}{l}-0.009 \\
(-1.28)\end{array}$ & $\begin{array}{l}-0.003 \\
(-0.19)\end{array}$ & $\begin{array}{l}-0.005 \\
(-0.31)\end{array}$ & $\begin{array}{l}0.000 \\
(-0.02)\end{array}$ & $\begin{array}{l}-0.002 \\
(-0.12)\end{array}$ \\
\hline LIQ & $\begin{array}{l}0.000 \\
(-0.04)\end{array}$ & $\begin{array}{l}0.000 \\
(0.00)\end{array}$ & $\begin{array}{l}0.000 \\
(0.04)\end{array}$ & $\begin{array}{l}0.000 \\
(0.03)\end{array}$ & $\begin{array}{l}0.012 \\
(0.65)\end{array}$ & $\begin{array}{l}0.010 \\
(0.54)\end{array}$ & $\begin{array}{l}0.009 \\
(0.55)\end{array}$ & $\begin{array}{l}0.005 \\
(0.31)\end{array}$ \\
\hline$\Delta \mathrm{VIX}$ & $\begin{array}{l}0.001 \\
(0.07)\end{array}$ & $\begin{array}{l}0.001 \\
(0.11)\end{array}$ & $\begin{array}{l}0.004 \\
(0.34)\end{array}$ & $\begin{array}{l}-0.002 \\
(-0.19)\end{array}$ & $\begin{array}{l}-0.020 \\
(-1.44)\end{array}$ & $\begin{array}{l}-0.017 \\
(-1.20)\end{array}$ & $\begin{array}{l}-0.015 \\
(-1.06)\end{array}$ & $\begin{array}{l}-0.016 \\
(-1.06)\end{array}$ \\
\hline$\Delta \mathrm{VIX}^{2}$ & $\begin{array}{l}0.003^{*} \\
(1.85)\end{array}$ & $\begin{array}{l}0.003^{*} \\
(1.84)\end{array}$ & $\begin{array}{l}0.002 \\
(1.63)\end{array}$ & $\begin{array}{l}0.002 \\
(1.65)\end{array}$ & $\begin{array}{l}0.003 \\
(1.27)\end{array}$ & $\begin{array}{l}0.003 \\
(1.25)\end{array}$ & $\begin{array}{l}0.002 \\
(1.00)\end{array}$ & $\begin{array}{l}0.003 \\
(1.24)\end{array}$ \\
\hline $\mathrm{SKEW}_{\text {opt } / C D S}$ & $\begin{array}{l}0.008 \\
(1.08)\end{array}$ & $\begin{array}{l}0.007 \\
(0.97)\end{array}$ & $\begin{array}{l}0.007 \\
(1.09)\end{array}$ & & $\begin{array}{l}0.017 \\
(1.23)\end{array}$ & $\begin{array}{l}0.012 \\
(0.96)\end{array}$ & $\begin{array}{l}0.013 \\
(1.12)\end{array}$ & \\
\hline $\mathrm{SKEW}_{B K M}$ & & & & $\begin{array}{l}0.002 \\
(0.46)\end{array}$ & & & & $\begin{array}{c}-0.001 \\
(-0.16)\end{array}$ \\
\hline DS & $\begin{array}{l}0.005^{* *} \\
(2.01)\end{array}$ & $\begin{array}{l}0.005^{*} \\
(1.82)\end{array}$ & $\begin{array}{l}0.004^{* *} \\
(2.01)\end{array}$ & $\begin{array}{l}0.005^{* *} \\
(2.22)\end{array}$ & $\begin{array}{l}0.011^{*} \\
(1.99)\end{array}$ & $\begin{array}{l}0.010 \\
(1.64)\end{array}$ & $\begin{array}{l}0.010^{*} \\
(1.90)\end{array}$ & $\begin{array}{l}0.010^{*} \\
(1.92)\end{array}$ \\
\hline Adj. $R_{c r}^{2}$ & 0.529 & 0.497 & 0.498 & 0.489 & 0.653 & 0.644 & 0.633 & 0.626 \\
\hline
\end{tabular}




\section{Table 11: Fama-MacBeth regressions (2/2)}

The table shows the second-stage coefficients from Fama and MacBeth (1973) regressions. The test assets are 25 book-to-market/size portfolios replicated using the stocks with available volatility spreads (Bali and Hovakimian, 2009) and smirks (Xing, Zhang, and Zhao, 2010), and 10 decile portfolios based on the DS measure in month $t-1$. The characteristics (portfolios averages in month $t$-1), are idiosyncratic volatility (Ang, Hodrick, Xing, and Zhang, 2006) (ivol), average 5-year CDS log-spread ( $\left.\operatorname{sprd}_{5 y r}\right)$, hybrid tail covariance (Bali, Cakici, and Whitelaw, 2014) ( $\left.\operatorname{cov}_{\text {tail }}\right)$, and changes in call/put implied volatility of An, Ang, Bali, and Cakici (2014) ( $\Delta$ cvol and $\Delta$ pvol). Adj. $\mathrm{R}_{c r}^{2}$ is the average adj. $\mathrm{R}^{2}$ of the second-stage regressions. The sample covers February 2006 to December 2015.

\begin{tabular}{|c|c|c|c|c|c|c|c|c|}
\hline & \multicolumn{4}{|c|}{ 2006-2015 } & \multicolumn{4}{|c|}{$2008-2011$} \\
\hline & (1) & (2) & (3) & $(4)$ & (5) & (6) & $(7)$ & (8) \\
\hline$\lambda^{0}$ & $\begin{array}{l}0.026 \\
(1.60)\end{array}$ & $\begin{array}{l}0.017 \\
(1.12)\end{array}$ & $\begin{array}{l}0.027^{*} \\
(1.67)\end{array}$ & $\begin{array}{l}0.018 \\
(1.08)\end{array}$ & $\begin{array}{l}0.017 \\
(0.64)\end{array}$ & $\begin{array}{l}0.012 \\
(0.45)\end{array}$ & $\begin{array}{l}0.015 \\
(0.60)\end{array}$ & $\begin{array}{l}0.003 \\
(0.13)\end{array}$ \\
\hline ivol & $\begin{array}{l}-0.138 \\
(-1.54)\end{array}$ & $\begin{array}{l}-0.134 \\
(-1.55)\end{array}$ & $\begin{array}{l}-0.155 \\
(-1.64)\end{array}$ & $\begin{array}{l}-0.143 \\
(-1.53)\end{array}$ & $\begin{array}{l}-0.249^{*} \\
(-1.78)\end{array}$ & $\begin{array}{l}-0.266^{*} \\
(-1.96)\end{array}$ & $\begin{array}{l}-0.282^{* *} \\
(-2.02)\end{array}$ & $\begin{array}{l}-0.236^{*} \\
(-1.74)\end{array}$ \\
\hline $\operatorname{sprd}_{5 y r}$ & $\begin{array}{l}0.243 \\
(0.91)\end{array}$ & $\begin{array}{l}0.120 \\
(0.48)\end{array}$ & $\begin{array}{l}0.204 \\
(0.78)\end{array}$ & $\begin{array}{l}0.053 \\
(0.20)\end{array}$ & $\begin{array}{l}0.142 \\
(0.37)\end{array}$ & $\begin{array}{l}0.078 \\
(0.20)\end{array}$ & $\begin{array}{l}0.122 \\
(0.32)\end{array}$ & $\begin{array}{l}0.010 \\
(0.03)\end{array}$ \\
\hline $\operatorname{cov}_{\text {tail }}$ & $\begin{array}{l}-0.009 \\
(-1.44)\end{array}$ & $\begin{array}{l}-0.011^{*} \\
(-1.85)\end{array}$ & $\begin{array}{l}-0.010 \\
(-1.55)\end{array}$ & $\begin{array}{l}-0.013^{* *} \\
(-2.06)\end{array}$ & $\begin{array}{l}-0.009^{* *} \\
(-2.03)\end{array}$ & $\begin{array}{l}-0.006 \\
(-1.08)\end{array}$ & $\begin{array}{l}-0.008^{* *} \\
(-2.04)\end{array}$ & $\begin{array}{l}-0.006 \\
(-1.17)\end{array}$ \\
\hline$\Delta \mathrm{cvol}$ & $\begin{array}{l}0.112 \\
(1.22)\end{array}$ & $\begin{array}{l}0.136 \\
(1.49)\end{array}$ & $\begin{array}{l}0.118 \\
(1.37)\end{array}$ & $\begin{array}{l}0.167^{*} \\
(1.83)\end{array}$ & $\begin{array}{l}0.156 \\
(1.22)\end{array}$ & $\begin{array}{l}0.173 \\
(1.23)\end{array}$ & $\begin{array}{l}0.197 \\
(1.55)\end{array}$ & $\begin{array}{l}0.134 \\
(1.02)\end{array}$ \\
\hline$\Delta$ pvol & $\begin{array}{l}-0.066 \\
(-0.74)\end{array}$ & $\begin{array}{l}-0.094 \\
(-1.09)\end{array}$ & $\begin{array}{l}-0.076 \\
(-0.89)\end{array}$ & $\begin{array}{l}-0.128 \\
(-1.46)\end{array}$ & $\begin{array}{l}-0.170 \\
(-1.28)\end{array}$ & $\begin{array}{l}-0.199 \\
(-1.33)\end{array}$ & $\begin{array}{l}-0.239^{*} \\
(-1.77)\end{array}$ & $\begin{array}{l}-0.149 \\
(-1.10)\end{array}$ \\
\hline MKT & $\begin{array}{l}0.001 \\
(0.18)\end{array}$ & $\begin{array}{l}0.004 \\
(0.50)\end{array}$ & $\begin{array}{l}0.001 \\
(0.07)\end{array}$ & $\begin{array}{l}0.002 \\
(0.23)\end{array}$ & $\begin{array}{l}0.008 \\
(0.64)\end{array}$ & $\begin{array}{l}0.008 \\
(0.60)\end{array}$ & $\begin{array}{l}0.008 \\
(0.58)\end{array}$ & $\begin{array}{l}0.011 \\
(0.77)\end{array}$ \\
\hline SMB & $\begin{array}{l}0.000 \\
(0.05)\end{array}$ & $\begin{array}{l}0.001 \\
(0.31)\end{array}$ & $\begin{array}{l}0.000 \\
(0.01)\end{array}$ & $\begin{array}{l}0.001 \\
(0.40)\end{array}$ & $\begin{array}{l}0.001 \\
(0.15)\end{array}$ & $\begin{array}{l}0.000 \\
(-0.10)\end{array}$ & $\begin{array}{l}0.001 \\
(0.14)\end{array}$ & $\begin{array}{l}0.000 \\
(0.11)\end{array}$ \\
\hline HML & $\begin{array}{l}-0.007^{*} \\
(-1.71)\end{array}$ & $\begin{array}{l}-0.006 \\
(-1.45)\end{array}$ & $\begin{array}{l}-0.005 \\
(-1.27)\end{array}$ & $\begin{array}{l}-0.004 \\
(-1.10)\end{array}$ & $\begin{array}{l}0.002 \\
(0.26)\end{array}$ & $\begin{array}{l}0.004 \\
(0.56)\end{array}$ & $\begin{array}{l}0.003 \\
(0.51)\end{array}$ & $\begin{array}{l}0.005 \\
(0.70)\end{array}$ \\
\hline RMW & & & $\begin{array}{l}0.000 \\
(0.00)\end{array}$ & $\begin{array}{l}-0.001 \\
(-0.23)\end{array}$ & & & $\begin{array}{l}-0.002 \\
(-0.58)\end{array}$ & $\begin{array}{l}-0.004 \\
(-0.74)\end{array}$ \\
\hline CMA & & & $\begin{array}{l}0.000 \\
(-0.03)\end{array}$ & $\begin{array}{l}0.000 \\
(0.03)\end{array}$ & & & $\begin{array}{l}0.000 \\
(-0.09)\end{array}$ & $\begin{array}{l}-0.002 \\
(-0.30)\end{array}$ \\
\hline UMD & $\begin{array}{l}-0.005 \\
(-0.49)\end{array}$ & $\begin{array}{l}-0.008 \\
(-0.84)\end{array}$ & $\begin{array}{l}-0.004 \\
(-0.42)\end{array}$ & $\begin{array}{l}-0.008 \\
(-0.83)\end{array}$ & $\begin{array}{l}-0.005 \\
(-0.31)\end{array}$ & $\begin{array}{l}-0.005 \\
(-0.28)\end{array}$ & $\begin{array}{l}-0.010 \\
(-0.57)\end{array}$ & $\begin{array}{l}-0.010 \\
(-0.56)\end{array}$ \\
\hline LIQ & $\begin{array}{l}0.003 \\
(0.38)\end{array}$ & $\begin{array}{l}0.002 \\
(0.20)\end{array}$ & $\begin{array}{l}0.000 \\
(0.05)\end{array}$ & $\begin{array}{l}0.000 \\
(-0.02)\end{array}$ & $\begin{array}{l}0.010 \\
(0.71)\end{array}$ & $\begin{array}{l}0.009 \\
(0.61)\end{array}$ & $\begin{array}{l}0.008 \\
(0.53)\end{array}$ & $\begin{array}{l}0.010 \\
(0.60)\end{array}$ \\
\hline$\Delta \mathrm{VIX}$ & $\begin{array}{l}0.005 \\
(0.43)\end{array}$ & $\begin{array}{l}0.000 \\
(-0.04)\end{array}$ & $\begin{array}{l}0.005 \\
(0.42)\end{array}$ & $\begin{array}{l}0.002 \\
(0.11)\end{array}$ & $\begin{array}{l}-0.012 \\
(-0.78)\end{array}$ & $\begin{array}{l}-0.016 \\
(-1.03)\end{array}$ & $\begin{array}{l}-0.016 \\
(-1.08)\end{array}$ & $\begin{array}{l}-0.023 \\
(-1.47)\end{array}$ \\
\hline$\Delta \mathrm{VIX}^{2}$ & $\begin{array}{l}0.002 \\
(1.17)\end{array}$ & $\begin{array}{l}0.001 \\
(1.07)\end{array}$ & $\begin{array}{l}0.002 \\
(1.16)\end{array}$ & $\begin{array}{l}0.002 \\
(1.15)\end{array}$ & $\begin{array}{l}0.002 \\
(1.05)\end{array}$ & $\begin{array}{l}0.002 \\
(0.98)\end{array}$ & $\begin{array}{l}0.002 \\
(0.87)\end{array}$ & $\begin{array}{l}0.001 \\
(0.57)\end{array}$ \\
\hline $\mathrm{SKEW}_{o p t / C D S}$ & $\begin{array}{l}0.006 \\
(0.93)\end{array}$ & & $\begin{array}{l}0.006 \\
(0.95)\end{array}$ & & $\begin{array}{l}0.011 \\
(0.96)\end{array}$ & & $\begin{array}{l}0.013 \\
(1.08)\end{array}$ & \\
\hline $\mathrm{SKEW}_{B K M}$ & & $\begin{array}{l}0.002 \\
(0.54)\end{array}$ & & $\begin{array}{l}0.003 \\
(0.59)\end{array}$ & & $\begin{array}{l}0.000 \\
(-0.07)\end{array}$ & & $\begin{array}{l}-0.002 \\
(-0.23)\end{array}$ \\
\hline DS & $\begin{array}{l}0.004^{*} \\
(1.75)\end{array}$ & $\begin{array}{l}0.005^{* *} \\
(2.05)\end{array}$ & $\begin{array}{l}0.004 \\
(1.51)\end{array}$ & $\begin{array}{l}0.005^{*} \\
(1.85)\end{array}$ & $\begin{array}{l}0.010^{*} \\
(1.88)\end{array}$ & $\begin{array}{l}0.010 \\
(1.64)\end{array}$ & $\begin{array}{l}0.011^{* *} \\
(2.04)\end{array}$ & $\begin{array}{l}0.010^{* *} \\
(2.09)\end{array}$ \\
\hline Adj. $R_{c r}^{2}$ & 0.461 & 0.453 & 0.487 & 0.475 & 0.568 & 0.560 & 0.609 & 0.613 \\
\hline
\end{tabular}




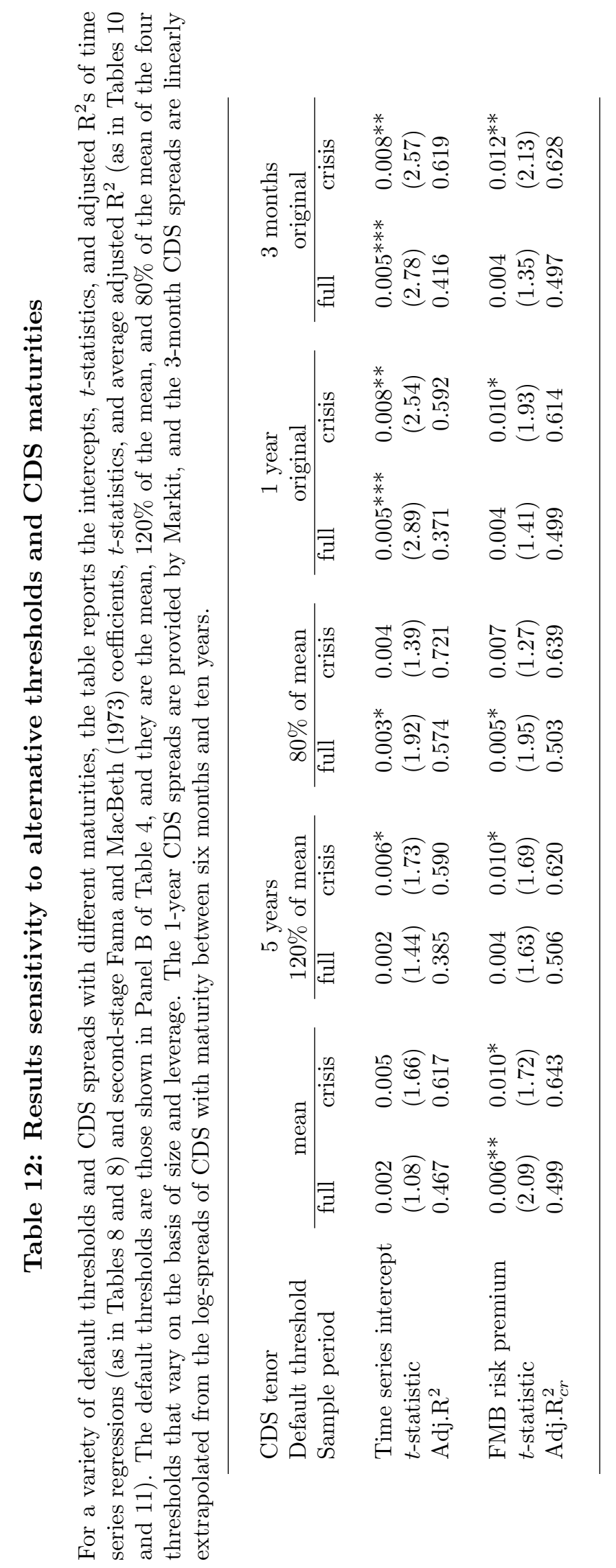

